\title{
THE USES, UNDERSTANDINGS, AND VALUES OF STUDENT \\ STRUCTURAL ASSISTING METATEXTS IN COLLEGE \\ FIRST YEAR COMPOSITION COURSES
}

\section{JOSEPH RYAN DUNDOVICH}

\section{Pages}

This thesis offers a look into the perceptions, views, and experiences of first-year composition students into being offered a large amount of choice/agency in their major summative writing projects, but also accountability and guidance during their process with resources called 'structural assisting metatexts'. With major question being the following:

- How do first year composition students use, understand, and value forms of structural assisting metatexts during the writing/creation process?

The two parts of the writing process that were specifically researched in conjunction with their correlating metatexts are a project's topic selection (with the Proposal metatext) and the writers' reflections to give their peers more insight as they peer review the project draft (with the Writer's Memo metatext). The data gathering and analysis were based in 'grounded theory methods.' Wherein, five student participants shared their answers to several open-ended questions through an initial and ending survey, as well as three recorded interviews. Their

responses were gathered, transcribed, coded, and preliminarily analyzed before any predictions or claims were done in the study. This meant that the study's resulting theories and large-scale codes, through being grounded in the data, came directly from the participants rather than the researcher or a literature review done prior to the data gathering. 
These resulting trends, almost entirely, came from the five most commonly recorded codes from the cumulative list of 15. Those five codes were, Caring/Passionate/Proud, Perspectives (Angles/Lenses/Opinions), Discussion/Elaborate/Elaboration, Structure/Accountability, and Process/Writer's Process.

Two sub-groups of the five most commonly recorded codes served as the basis for the analysis chapters. The first three listed codes above were grouped together based on their usage when describing how metatexts impacted the interactions from writer to reader. In this study, it was person to person communications and their impact on the perceived benefits the participants felt they had. The second sub-group (the latter two codes) had codes that were more solitary and metacognitive in nature. These quotes featured participant reflections on how their ideas/actions adapted and molded through the structure of metatexts and written/oral reader feedback.

From these findings, two reciprocal relationships were discovered to be akin to a mathematical concept, called a Möbius strip. The first Möbius strip relates to how the individualistic features of a writer using a structural assisting metatext, result in writerreader/classroom communal benefits. The second Möbius strip discusses the interplay between student writers having agency over the content of their project drafts and corresponding metatexts, to the deadlines and required structural elements of their work.

Finally, a high level of interest for more research of metatexts and the feedback received by student writers to be done is detailed. Whether it be in different age group/academic settings, subject areas, or differing summative assessments that metatexts are paired with. The recommendations for fellow educators are to make use of structural assisting metatexts, model the effort and care that student writers desire in feedback from their readers, show enthusiasm for 
the choice and resulting variance amongst the drafts paired with their metatexts, and stick to limited structural requirements to ensure accountability for all parties involved in the process.

KEYWORDS: Agency, Empirical-Qualitative Research, First-Year Composition, Grounded Theory, Individualization, Memos, Peer Discussions, Peer Review, Project Proposals, Reflective Practices, Resources for Summative Assessments, Student Choice, Structural Assisting Metatexts, Writing Process, Möbius Strips 
THE USES, UNDERSTANDINGS, AND VALUES OF STUDENT

STRUCTURAL ASSISTING METATEXTS IN COLLEGE

FIRST YEAR COMPOSITION COURSES

JOSEPH RYAN DUNDOVICH

A Thesis Submitted in Partial

Fulfillment of the Requirements

for the Degree of

MASTER OF SCIENCE

Department of English

ILLINOIS STATE UNIVERSITY 
Copyright 2020 Joseph Ryan Dundovich 
THE USES, UNDERSTANDINGS, AND VALUES OF STUDENT

STRUCTURAL ASSISTING METATEXTS IN COLLEGE

FIRST YEAR COMPOSITION COURSES

JOSEPH RYAN DUNDOVICH

COMMITTEE MEMBERS:

Bob L. Broad, Chair

Ricardo C. Cruz 


\section{ACKNOWLEDGMENTS}

First, I owe an astronomical amount of thanks and gratitude to my advisor, Dr. Bob Broad. My 'discovery' of the Writer's Memo, and truly seeing the potential of what peer review, instructor feedback, and having more open ended assignments can be when the writers/creators are provided with trust and format, would not have been possible without taking Broad's ENG 246 (Advanced Composition) course during my sophomore year of college. Beyond our initial classroom experience, Dr. Broad has been a calming influence during my journey of being an educator and how I adjust my workload to manageable degrees.

Another calming influence on the educator I've become has been Professor Ricardo Cortez Cruz, my second reader. Through taking multiple creative writing courses and several genuinely fulfilling hallway conversations, Professor Cruz has been/will be a person I think of whenever I need to step back and calm my emotions in any area of life. In regards to composition classrooms, his courses instilled the value and effort I make to establish positive and engaging classroom communities, and the tangible impacts they can have on the quality of work in and out of academics.

Thank you to my family, lifelong friends, and graduate school friends (especially my trivia night team, ENG 494, and ENG 497 peers) for their support and openness to discussing my, often long-winded, thoughts on pedagogy and socialization practices.

To Dr. Christopher Watson and Mr. Ed Uhrik, thank you both for your compassion and conversations during the time of my life where I was contemplating what I wanted to do for career, and even if I had the capabilities to be a teacher. I hope this study can serve as a form of evidence, that our times together have absolutely paid off in full in my career as an educator. 
Lastly, to my five student participants, Aspen, Brian, Leah, Scotty, and Tracy, thank you for your gracious and thoughtful involvement in this study. I've heard that having an 8:00 AM gen-ed class during the first semester of college can be a mixed-bag for teachers and students. In our case though, it ended up being the most enjoyable college course I taught as a graduate student. The privilege of having students from this course have roles in my Master's Thesis cannot be understated. As this thesis is also able to serve as a reminder of the quality work, conversations, and memories that the fall semester of 2019 gave us as students, writers/creators, and overall people. I couldn't have asked for a more fulfilling experience gathering and analyzing your articulate and honest reflections.

J.R.D. 


\section{CONTENTS}

Page

ACKNOWLEDGMENTS

FIGURES

CHAPTER I: INTRODUCTION: METATEXTS, A RELATIVELY UNKOWN

RESOURCE FOR ALL STUDENTS AND WRITERS 1

Opening of the Thesis and Context for Metatexts 1

$\begin{array}{ll}\text { Review of Literature } & 7\end{array}$

Methods and Theories Utilized $\quad 10$

$\begin{array}{ll}\text { Chapter Outlines } & 15\end{array}$

$\begin{array}{ll}\text { Chapter I - Introduction } & 15\end{array}$

Chapter II - Literature Review 15

Chapter III - Methods Used in Study 16

Chapter IV - Analysis of Findings Part One 16

$\begin{array}{ll}\text { Chapter V - Analysis of Findings Part Two } & 17\end{array}$

$\begin{array}{lr}\text { Chapter VI - Conclusion } & 18\end{array}$

CHAPTER II: LITERATURE REVIEW: A LACK OF FORMAL STUDIES ABOUT

AGENCY IN WRITER FEEDBACK 19

$\begin{array}{ll}\text { Writer's Memo Related } & 20\end{array}$

Reader Feedback for Writing Completed in Non-FYC Courses 24

The Acknowledgement of Web Based Courses 33

Effort and Agency in Students Related 35

Writing Assessment/Assessment in General Related 38 
CHAPTER III: RESEARCH CONTEXTS AND METHODS: THEORY GROUNDED IN PRACTICIPANT REFLECTIONS AND INTERACTIONS WITH METATEXTS AND THEIR PEERS

My Methodological Framework Partners in This Study 41

Grounded Theory/Narratives in Writing and Research 44

Involvement of Student Voices/Emphasis They are Given in This Study 46

My Pedagogy Behind Sharing My Own Metatexts in FYC Courses 51

My Pedagogy Behind Practicing the Metatexts in FYC Courses 54

Putting It All Together in My Notetaking and Data Grouping Practices 57

$\begin{array}{ll}\text { Excerpt of Specific Breakdowns for Initial Survey } & 60\end{array}$

$\begin{array}{ll}\text { Methods Conclusion } & 61\end{array}$

CHAPTER IV: ANALYSIS OF FINDINGS PART ONE: STUDENTS VALUE THE

APPARARENT CARE AND EFFORT A WRITER AND/OR PEER REVIEWER

GIVES AND THE DISCUSSIONS THAT SPARK FROM IT 62

Overall Code List Elaboration and Intro to Takeaways Related to Common Codes

Dealing with Interacting with Other People 62

The Code of Caring/Passionate/Proud Within the Effort Given and Received by

$\begin{array}{ll}\text { Students } & 67\end{array}$

The Code of Discussion/Elaborate/Elaboration to Create and Build on

Understandings

The Code of Perspectives (Angles/Lenses/Opinions) to Broaden and Reaffirm the Writer 
CHAPTER V: ANALYSIS OF FINDINGS PART TWO: STUDENTS REFLECTING

ON, AND/OR CHANGING, THEIR STYLES BASED ON THE MIXTURE OF

AGENCY AND ACCOUNABILITY

Overall Code List Reminders and Intro to Takeaways Related to Common Codes

Dealing with Interacting with Formatting of Metatexts/Writing Styles

The Code of Structure/Accountability to Keep Students on Track Beyond

Editorial Work

The Code of Process/Writer's Process to Move Thoughts From the Mind to the

Paper

CHAPTER VI: CONCLUSION: RECIPROCAL BENEFITS FOR STUDENT WRITERS

AND READERS FROM METATEXT INCLUSION IN THEIR INDIVIDUAL AND

COLLABORATIVE WRITING PROCESSES

Overall Reflection on My Experience in This Research Study

Connections Between Findings in Chapters IV and V (Purpose and Learning)

Connections Between Chapters IV and V (Contrasting Negative Prior

Experiences or Alternative Learning Environments)

First Resulting Möbius Strip: Communal Benefits from Individualistic Metatexts

Second Resulting Möbius Strip: Agency in Divergent Writing With Similar

Requirements

Similar Future Studies and/or Research of Metatexts and Structurally Assisted

Agency

Applications in Other Educational Settings

Applications for Teachers Assigning Papers or Projects 
Final Answer to The Research Question, For Now...

WORKS CITED

APPENDIX A: UNIT 1 RUBIRC (PAIRED WITH PART 1 DRAFT AND WM IN

APPENDIX B AND C)

APPENDIX B: UNIT 1 SAMPLE WRITER'S MEMO (PAIRED WITH SAMPLE SONG

IN APPENDIX C)

APPENDIX C: UNIT 1 SAMPLE SONG LYRICS (PAIRED WITH SAMPLE WM IN APPENDIX B)

134 


\section{FIGURES}

Figure

Page

1. Writer's Memo (WM) Template 5

2. Proposal Introduction Directions 6

3. Student Written Survey Questions for Thesis 13

4. Student Interview Questions for Thesis 14

5. Instructor's Sample WM from Their Own Undergrad 52

6. Instructor's Sample Proposal for Completed Conference Presentation 54

7. Instructor's Sample WM for Myself as a Writer 55

8. Response Memo (RM) Template $\quad 65$ 
CHAPTER I: INTRODUCTION: METATEXTS, A RELATIVELY UNKNOWN RESOURCE

FOR ALL STUDENTS AND WRITERS

\section{Opening of the Thesis and Context for Metatexts}

- $\quad$ "One of my students called the student-teacher memo an invaluable tool for going 'behind the paper.' That phrase, wonderfully concise, explains the purpose of the technique: it is intended to take both student and teacher behind the paper, into the composing process which produced the draft." - (Sommers 77).

That tool, the Student-Teacher Memo, successfully utilized above in a composition course taught by Jeffrey Sommers, writing studies scholar and former English professor at Miami University, offers an additional layer of context and dialogue opportunities for any project. This added 'layer' gives structure in the form of its layout, but also agency in what the student is writing about and how they describe the writing process to allow themselves and outsiders to actually go not only 'behind the paper', but also 'into the mind' of the person or people the paper was crafted by.

The structure Sommers uses for the Student-Teacher Memo follows a loose format in that, "Along with each writing assignment, my students receive a brief assignment sheet for the (Student-Teacher) memo, consisting of several questions about their written drafts, some of which ask them to evaluate their text, and some of which ask them to describe and comment on the composing process. When the students hand in the draft for me to comment upon, they also hand in their completed memos, which I read before responding to their project." (77-78). As a result of the Student-Teacher Memo usage, the reader's initial understanding of the work is supported as an outsider to the text's creation. As they are getting a reflective piece to see explicit processes of the writing. Given this, the understanding of the ideas that shape the content 
of the draft, is maximized. Which for readers that are going to be evaluating and/or providing feedback with the help of this 'structural assisting metatext' is truly an asset to the development of the written main texts they are paired with and the minds from which they come from.

Before I move on any further I want to define what I mean by 'metatext.' A term I coined from the terms metacognitive and text. As a result, I would define a metatext as, "A text that describes and/or discusses another, often larger, text." The added on words of 'structural assisting', function as adjectives to specify the type of metatext being used. While they give structural assistance, the voice of the writer and thus life of the text (and main draft that the metatext is paired with) are still given a high amount of freedom and independence from whatever instructor, administrator, or publishing agent the text is bring written/created for or given to the writer as a project by.

The core difference between Sommers's (among other scholars') structural assisting metatext, the Student-Teacher Memo, and the metatexts that I myself use in my first year composition (FYC) classroom is the audience it is primarily written for. Sommers, and fellow educators Anthony Bryan Bardine and Anthony Fulton, have the dialogue from these texts only between the student writer and the instructors. In the case of my own pedagogy on the writing/creation processes at various institutions I've worked at, Illinois State University at the time of this research, my structural assisting metatexts also interact with the student writer and the instructor; but at times, the student writer's peers in the classroom. Which leads to the value I have for metatexts being used at multiple stages of the writing/creation process. For the sake of this study, my research will involve the two structural assisting metatexts I have utilized the most often in my English composition classrooms. Which I call the 'Writer's Memo' (Figure 1) and the 'Proposal' (Figure 2). 
Specifically, the Writer's Memo (WM) structural assisting metatext helps provide structure and agency with the peer review/self-reflection activities of a project after a good portion of the draft has been written between peers in the same class completing similar projects. By asking students questions about what they have done (their process) so far in the accompanying draft, the draft's strengths, the desired areas of feedback from peers and/or questions for their peers, and any areas they are not comfortable discussing further or do not want constructive criticism on depending on the content of the work, which I call 'No Go Zones'. While the Proposal structural assisting metatext asks questions, as the name suggests, that have the writer 'propose' an idea they have based on a summative assessment prompt with varying levels (typically minimal) content requirements. So the Proposal serves as a way to force more hesitant or unsure writers to pick a topic to start with rather than procrastinating on one. Additionally, the writer offers a couple of backup options that also fit the assessment prompt. Most importantly however, the students offer at least three ways in which either the instructor, their peers, themselves, or the class schedule can help them reach their definition of success on this given writing project. Whether it be in-class work days, more examples from the instructor, resource explained or shown off, schedule reminders, or requests for maximum effort from their peers, these questions add another layer to the writing process in terms of how writers metacognitively consider and reflect on their own abilities and desires as creators and workers in general.

I would define the Writer's Memo, based on a combination of the words of Bob Broad, English professor at Illinois State University, and Sommers, who Broad cites as an inspiration behind his own adjusted version of the Writer's Memo (and not the Student-Teacher Memo) as, 'A written document to a reviewer of the composer's work to give context of the work in regards 
to the their process, feelings on the work in regards to strengths and weaknesses, and desired areas for the most focused feedback from their readers.' Just like the working definition of structural assisting metatext elaborates on, the Writer's Memo offers a mixture of structural guidance and focus without removing much of the freedom that a writer has to the life of their work. Key questions to help structure the writer's reflection of the draft that is being reviewed as well as what the writer would like the most focused feedback on are crucial components of what makes this fit the working definition of a structural assisting metatext.

The Proposal on the other hand, is a much broader concept to narrow down. In part, it came from the concept of the Writer's Memo in offering guidance, accountability, and structure to the writer/creator. The core difference being that it comes at the start of the writing process rather than a revision based stage for a partially/fully written draft.

Within the same piece discussing his usage of the structural assisting metatext, the Student-Teacher Memo, Sommers believes that these kinds of communications can help the concerns and problems run into during many types of English courses:

Freshmen composition instructors teaching a process-oriented course rather than a product-oriented one face a number of problems. How can they effectively make students aware of how their own composing occurs? How can instructors respond in an informed way to students' developing drafts? How can instructors reduce students' anxiety sufficiently so that they can learn how to improve as writers? (77).

I'd like to think through offering students structural assisting texts to help them in their creations (writing projects or not) will help make this transition and knowledge making process (of FYC courses) all the more beneficial. While hopefully providing at least a possible answer to 
the thought provoking statement Sommers includes with his rationale for involving his own kind of metatext so deeply in his pedagogy.

In the courses that I have taught thus far in my career as an educator, the implementations of the Writer's Memo and Proposal have gone extremely well. However my thoughts have also expanded to finding out, in a more formal manner, whether or not my students feel as confident as I do about the effectiveness of these textual resources. Given these thoughts and my desire to reach my students in ways that go beyond the English classroom, as a vast majority of them are not English majors, my research question for this research study became, "How do first year composition students use, understand, and value forms of structural assisting metatexts during the writing/creation process?"

Figure 1: Writer's Memo (WM) Template

Writer's Memo Outline Format

(Follow Word and Content Requirements to Receive Full Credit!)

Your Must Have at Least a Draft with the Minimum Requirements to Peer Review

1. What you did so far (describe your writing processes to this point).

50 Words Minimum 


\begin{tabular}{|l|l|}
\hline 2. & What you like about the current draft \\
(specific strength[s]) & \\
& Three Strengths \\
& 45 Words Total \\
Minimum Combined & \\
\hline 3. What you want from your readers (two \\
or three specific and well-developed \\
questions and/or points of focus) \\
Two or more Questions \\
75 Words Minimum. \\
Provide Specifics Such \\
as Quotes, Pages, \\
and/or Paragraphs. \\
\hline 4. No Go Zones (Things you don't want \\
constructive criticism on. No reason \\
required, but if you're comfortable \\
explaining why, I'm sure it would be \\
helpful :) \\
YES/NO MINIMUM
\end{tabular}

Figure 2: Proposal Introduction Directions

\section{Proposals!}

Our projects will be very open ended (something I value and hope you do too) but will all have a personal approach based on who you are, your experiences, and what you're interested in for your career, hobbies, and social life. Because of this, I want to be able to help, provide proper resources, ideas, have your peers be able to help you, 
and have us fully think through what will go into each of your project ideas.

Additionally, as a creator, having to justify your desire to work on something should make you that much more passionate about it! It makes you consider if you have fully thought through if an idea can fit into the specific genre/prompt we are working with. I'd rather restart a project in the brainstorming stage before I spend time and effort working on a presentation when I later find out the teacher won't approve of it or it doesn't seem interesting to me anymore.

How They'll Work: For each of our 3 major units, you will have to submit a proposal early on in the process. Length requirement varies for each unit, as you'll be asked to answer the following question about your idea for a project/aspect of a project either as an assignment or in person meeting with Joey depending on the unit

1. Why this idea? What inspired you to come up with this idea?

2. What are some other ideas you have for this in case you run into obstacles (at least two other options to fall back on)

3. What would you like from your instructor and classmates to help you in meeting your definition of success for this project (at least 3 suggestions or ideas)

Review of Literature

There were two pieces of literature that matched the heart of what I believe metatexts are useful for. The first features the previously mentioned Jeffrey Sommers and his Student-Teacher Memo. In his article, published in a 1988 issue of College Composition and Communication, Sommers feels this kind of structural assisting metatext is an excellent answer to the concerns of many process-orientated FYC course teachers. He immediately establishes the purpose to his readers in the same way he would to the classes the memo is utilized within: 
In these opening day instructions I make sure to comment on the memos' two major functions: they focus my attention as a reader on the parts of the students' papers about which they feel the strongest need for response, and they also encourage students to think about what they have written and how they have gone about writing it. By being candid about the purposes of the memos, I can begin to present them for what they are: an opportunity for students to take advantage of, rather than another judgment tool for the teacher. (78).

The humility shown by Sommers to his students is a core element of why I believe these kinds of metatexts (memos as he calls them) appear to be so effective in the scholarly work that is out there about them. It acts as a way to provide focus, purpose, and clarity, while also allowing for variation in the educational settings they are used within. He further states that the core questions (four total) within the memo can change depending on the type of writing the students are doing (79). This effort shows a clear understanding of the need for different kinds of writing benefiting from adjustments either in what the writer writes in a memo, or how the memo is structured for the writer to best make use of. While my own structural assisting metatexts, the Writer's Memo and the Proposal, don't change their structure or questions depending on the genre/type of writing being completed, the variation and acknowledgement of writer individuality is kept at the forefront of the two metatexts' existence as the choices they make on how to answer the questions posed by either are completely up to them.

Another pair of scholars that utilize structural assisting metatexts are educators Anthony Bryan Bardine and Anthony Fulton, in their work concerning the usage of the structural assisting metatext they call 'Revision Memos,' which has components that are in line with my own Writer's Memo format, but function more closely to Sommers's 'Student-Teacher Memo'. 
Bardine and Fulton feel that the biggest factor in ensuring their metatext is successfully used, which they instead refer to as self-reflective writing, is the establishment of a supportive and creative classroom community. They further elaborate by stating "environment is also a factor. Personalizing the students' work and establishing the classroom as a community of writers provides the ideal conditions for self-reflective writing," (150). Similarly, Bardine and Fulton point out the importance of finding a balance between the structure provided by the resources given to student writers, but also allowing the students room to feel as if they have the freedom to share with their readers what they are truly interested in, or feel is a worthwhile pursuit when reflecting on a piece of work they have completed.

The emphasis for Bardine and Fulton's structural assisting metatext is on students taking the feedback from instructors and consciously reflecting on why certain revisions were made draft to draft of a text's life. Though the reasoning for this additional resource is slightly adjusted from my Writer's Memo usage in a peer review of a preliminary draft, their Revision Memo's ability to help develop a written text, and a writer's reflective abilities, are still valued in this structural assisting metatext, "To overcome most challenges, teachers must clearly state the purpose and rationale for all self-reflective writing, implement collaborative learning, clarify the audience, and tailor assignments to promote self-development" (150). This promotion of selfimprovement with structural guidance from an instructor is what appears to make this kind of task so beneficial to their classrooms. Students who successfully take into account the comments from their instructor as written on the Revision Memo accompanying the main project, appear to have a further communicative nature between writer and reader, "because of the structure of the revision memos, she [a student of one of the authors] is reading the comments written on her papers, something many students fail to do, and using them to improve future drafts." (151). 
Again, every action involving this fully functional metatext is clearly tied to tangible benefits to the student writer that can easily be applied to their current project, rather than unstructured peer or instructor feedback experiences for novice writers, those that have not deeply studied composition related theory, or those that do not have the inclusion of structural assisting metatexts during various stages of the writing process.

Unlike Bardine and Fulton's stated purpose of their Revision Memo, the Writer's Memo and Proposal within my composition classrooms have the purposes of describing a larger project. This is to allow readers, and the writer themselves, to see their feelings and goals for a current piece of writing. Additionally, the writers are also reflecting on what they have done so far in the process of creating said project in the case of the Writer's Memo. Whereas in the case of the Proposal, the feelings and processes described are about an idea for a project in the preliminary brainstorming stages.

\section{Methods and Theories Utilized}

By utilizing concepts and methods found within both grounded theory and empiricalqualitative research when answering my research question, I believe the analysis presented in this study offers appropriate and thought provoking findings for the composition studies world, and teachers of all content areas. Firstly, the methodology of grounded theory originally came to my attention via the words of Kathy Charmaz, sociology professor and director of Sonoma State University's Faculty Writing Program, who writes that, “Grounded theory methods consist of systematic, yet flexible guidelines for collecting and analyzing qualitative data to construct theories from the data themselves. Thus researchers construct a theory 'grounded' in their data...Grounded theory methods lead you to make early stops to analyze what you find along 
your path.” (1). In a somewhat ironic way, the systematic and flexible framework of grounded theory methods mirror my own utilization and preliminary analysis through the structural assisting metatexts employed in my FYC courses. Almost mandating that a grounded theory framework was a part of this thesis given what the purpose of the material being studied was about.

What also helped me get to this mystical destination of a theory in response to my research question, I decided I had to involve another theoretical concept in my study. By asking myself the following questions when I selected my topic. What will my data by focused on? How will I separate my data? What data will be viewed as valuable and worthy of further analysis?

Given these questions, the other methodological framework I ended up employing in my data collection and analysis was empirical-qualitative research. Bob Broad explains that, "The primary focus of the empirical-qualitative researcher is relationships and interactions among people, not published texts.” (199). Despite my obvious emphasis on structural assisting metatexts in this study, I indeed was (and probably always will be as an educator) more focused on the interactions that are either created or impacted by their utilization among first year composition students and those that view their work. To be more specific, the interactions that occur between the students and their peers, the students and the instructor, and each student's internal dialogues.

Empirical-qualitative research was able to answer another one of my concerns about categorizing and placing subsequent value on each piece of data in a study interested in the interactions of people surrounded by written texts. Broad follows up with stating that these actions are done by an empirical-qualitative researcher when they, "usefully and meaningfully 
separate out the context-freeing (objectivist, experimentalist, quantitative) from the contextpreserving (interpretive, naturalistic, qualitative) methods of analysis, and among those using words as our chief kind of data, we distinguish the textual from the empirical." (199). This separation technique perfectly pairs with the core beliefs of grounded theory, as the conclusions of the study are clearly organized and acknowledged as being based in the data rather than preconceived or clouded judgements. These judgments can stem from the researchers' prior experiences and/or the plentiful studies they might have read before working on their own methods and preliminary data collection.

In terms of who my data specifically came from, several of my students within a section of ENG 101 (one of ISU's FYC course options) I taught during the fall 2019 semester graciously volunteered, and five were ultimately selected to participate in the empirical-qualitative research of my study. These data collection methods consisted of an opening survey centered around their prior experiences with agency and peer review (Figure 3), three semi-structured interviews concerning each of the three major class unit summative assessment of a genre of writing (Figure 4), and a closing survey (also Figure 3) that asked the participants to reflect on their experiences concerning the research question in regards to the semester as a whole.

From these five collections of qualitative data, I developed and tracked a list of coded terms. Charmaz feels that "As grounded theorists, we study our early data and begin to separate, sort, and synthesize those data through qualitative coding. Coding means that we attach labels to segments of data that depict what each segment is about." (4). I define coded terms as repeated words (and some of their synonyms) taken from the answers student participants gave when describing their feelings and experiences with the structural assisting metatexts and the communications that resulted from them. Thankfully, the research methods I utilized allowed my 
data and I the agency to take note of what language came up most frequently to document a list of coded terms. This list led to the answers to my research question, and was able to interact with previously published studies. Just like the structural assisting metatexts I studied were supposed to do for the student writers that interacted with them, my asking of the question, 'How do first year composition students use, understand, and value forms of structural assisting metatexts during the writing/creation process?' offered a way to hear how much structure and agency they preferred as they navigated writing in more complex and well-rounded ways.

Figure 3: Student Written Survey Questions for Thesis

\section{Opening Survey Questions for Joey Dundovich's Metatext Use, Understand, and Value Study \\ 1.Describe your experiences with peer review in prior classes, or classes you are currently taking that are not ENG 101. What were your major takeaways? Did you feel like these experiences were beneficial? If so, how? If not, why do you believe they were done? \\ 2.Describe your prior experiences with suggesting, proposing, or offering up ideas for major projects to an instructor outside of ENG 101. What were your major takeaways? Did you feel like these experiences were beneficial? If so, how? If not, why do you believe they were done? \\ 3. If you had to describe what you think of when you hear peer review in ONE word prior to ENG 101, what would it be and why?}

4. What do you do during the early stages of a project or major class assignment? What works best for your brainstorming process as a writer/creator and what doesn't work for you?

5. Prior to being in ENG 101, did you feel like your voice is heard and listened to by your peers when you have engaged in peer review? Why or why not?

6. Prior to being in ENG 101, did you feel like you were encouraged to think long term about a project/paper once the project was assigned? Do you like long term thinking when working on a project/paper? Why or why not?

Ending Survey Questions for Joey Dundovich's Metatext Use, Understand, and Value Study NOTE: Please read your opening survey questions first before answering these questions in order to properly reflect on your experiences in ENG 101, and the utilization of metatexts (Proposals and Writer's Memos). 
1.Describe your experiences with the Writer's Memo in ENG 101. What were your major takeaways? Did you feel like these experiences were beneficial? If so, how? If not, why do you believe they were done?

2.During ENG 101, Describe your experiences with the Proposal structured questions. What were your major takeaways? Did you feel more accountable than if you had not had to do the proposal questions? Why or why not?

3. At the end of ENG 101, If you had to describe what you think of when you hear peer review in ONE word, what would it be and why? Did this word change or remain the same compared to the word you used at the start of this study? Why do you think this change happened or not?

4. When using the structured questions for the Proposal in ENG 101, did this help or hurt how you previously thought out your ideas for a long term project/paper? Why or why not?

5. During ENG 101, did you feel like your voice was heard and listened to by your peers when you have engaged in peer review? Why or why not? Did the Writer's Memo come into play during your face to face interactions with peer reviewers?

6. During ENG 101, did you feel like you were encouraged to think long term about a project/paper once the project was assigned? Did you like the usage of a Proposal in ENG 101 to encourage long term thinking about a project/paper?

Figure 4: Student Interview Questions for Thesis

Interview \#1, 2, 3 Questions for Joey Dundovich's Metatext Use, Understand, and Value Study

1. Describe your experiences with the Writer's Memo in ENG 101 during the most recent Unit. What specifically was or was not beneficial of your experience?

2. During this most recent ENG 101 Unit describe your experience using the Proposal structured questions. Did you feel more accountable than if you had not had to do the Proposal questions? Why or why not?

3. During this most recent ENG 101 Unit describe how your peers' Writer's Memos helped or did not help you when reviewing their work.

4. Did your original idea you had when writing your Proposal for Unit \#1 stay the same or change when you submitted the final draft? Did you feel like your voice was heard looking back at question number three on this Proposal? Question three being, "What would you like from your instructor and classmates to help you in meeting your definition of success for this project?" 
5. During this most recent ENG 101 Unit did you feel like your voice was heard and listened to by your peers when you have engaged in peer review? Why or why not? How did the Writer's Memo factor into or impact your face to face interactions with peer reviewers?

6. During this most recent ENG 101 Unit do you feel that the genre of the major project/paper (creating your own song lyrics) impacted how you utilized the Writer's Memo and how you answered the Proposal structured questions? Why or why not?

7 Any additional information you'd like to say on the WM or Proposal during this Unit?

\section{Chapter Outlines}

\section{Chapter I - Introduction}

Introduces the reader to the definitions and forms of 'Structural Assisting Metatexts' as well as the other names scholars call them by. The two focused on in this study, the 'Proposal' and the 'Writer's Memo' are further explored. Some of the uses of structural assisting metatexts in composition classrooms are described and looked at with great pedagogical potential and agency by the instructors that utilize them. An explanation of the importance of this thesis research is given. Which is to learn more about what the composition students that are required to engage with these resources feel in terms of their understandings, uses, and values given to these metatexts that allow them a combination of structure and agency at various points of their writing processes.

\section{Chapter II - Literature Review}

Expands upon the earlier references to scholars that have used forms of metatexts in their own classrooms as well as other methods of allowing students structure and agency within writing environments. Beyond the work of Sommers and Bardine and Fulton, the lit review will present studies involving reader feedback completed in settings other than first year composition, acknowledging writer-reader communications that take place in online courses, studies into the 
perceptions of effort and its connection to agency, and an overall look at scholars' opinions on writing assessment in general.

\section{Chapter III - Methods Used in Study}

Defines and applies the two core methodological frameworks, 'Grounded Theory' and 'Empirical-Qualitative Research', that were employed in the data collection formats and analyses in regards to the major research question. Afterwards the involvement of my student participants, and my own pedagogy of crafting/sharing examples of these metatexts is explained and justified. The resulting coding process and timeline of the data collection is elaborated on given the style of the FYC course this study was completed in.

\section{Chapter IV-Analysis of Findings Part One}

Analyzes the data and subsequent findings for three of the five most commonly referenced and used codes. The three focused on in this part were grouped together based on the context the codes were quoted in being directly tied to a writer's socialization with other human beings responding to/discussing the drafts and/or metatexts they were paired with. For the code of 'Caring/Passionate/Proud' the student participants showed a high level of concern or appreciation depending upon the perceived amount that their peers 'cared' about these portions of the project. Next, the code of 'Discussion/Elaborate/Elaboration' was described by the students as an enjoyable experience when, while an extra piece of work, follow up conversations or explanations occurred because of their usage of either metatext. And the final socialization code of 'Perspectives (Angles/Lenses/Opinions)' students placed a high level of value on having other people involved in the making of their projects. For non-major courses, such as first year composition, the vast amount of interests are amplified even more given the course is a general education requirement. So it is a huge benefit to the usefulness of metatexts to have seen that 
students appreciate the increased socialization that these resources promote through the three grouped codes, that were said so often by the participants.

\section{Chapter V-Analysis of Findings Part Two}

The final two of the five most frequently used codes were used in a more solitary, cognitive, and rhetorical nature for individual student compared to the collaborative interactions of the previous three. Crossover connections did exist between the two groupings, and are viewed in detail within the conclusion chapter, but it was important to view the two groupings by themselves to accurately present the later comparisons. For the code of 'Structure/Accountability' it served as a chance for students to reminisce on the frequently more restrictive qualities of their prior courses. Conversely, this code was used to describe their (often first time) experiences with a high level of freedom in terms of what their projects topics were about and how they structured the projects. Where the metatexts came into play for this code, was the way students appreciated the accountability they were held to as they progressed with their projects, and consciously had to reflect on their work at multiple points of the text's life. The closely related code of 'Process/Writer's Process' factored into the metatexts in regard to how the students used their agency to answer the open ended prompts within the Proposal and the Writer's Memo. By the antecedent writing processes students made the choice to adjust, maintain, or completely change based on the inclusion of structural assisting metatexts, they were able to reflect on their own decisions as they moved through the three major unit projects of the FYC course this study took place within. The same can be said with how they responded to the accountability measures outlined within each metatext. 


\section{Chapter VI - Conclusion}

The final chapter offers an overall reflection by myself on completing all of the components of preparing to, collecting, and analyzing the data with a grounded theory and empirical qualitative research approach. As eluded to in Chapter V, connections between the previous two chapter groupings of the most prominent codes are explicitly made. These connections are related to the shared both groupings had of acknowledging purpose, learning opportunities, and contrasting negative prior experiences/alternative learning environments. After these connections are described, two reciprocal relationships (concepts called Möbius strips) are described as a result of successful metatext usage. Following this, I offer my adjustments and hopes for future studies in similar or different educational settings directly related to structurally assisted agency through metatexts. I then transition into presenting applications of my findings to any teachers that have their students complete summative assessments in the form of papers or projects while understanding the differing levels of agency these educators are offered by their schools and administrations in what/how they assess of their students. I then offer final words on how each of the five most prominently used codes by my student participants offered a well-rounded description of how my first-year composition students used, understood, and valued having structural assisting metatexts involved in their writing/creating processes. 


\section{CHAPTER II: LITERATURE REVIEW: A LACK OF FORMAL STUDIES ABOUT AGENCY IN WRITER FEEDBACK}

The review of literature for this study is separated into four distinct areas because I had trouble finding, and can only assume that there are very few studies and/or published applications of the concepts of Structural Assisting Metatexts, mixing structure with agency in the writing/creation process. Writings describing usages of the Writer's Memo, agency emphasized project proposals, or synonyms of any of the preceding concepts were scarce through academic libraries and online databases I consulted during my research. While this gave me a high level of excitement for the potential impact this piece can have in the education world, it made me utilize more abstract applications of the aspects of the writing process. And fairly unexpected codes that will later be discussed within the Methods and Analysis of Findings portions.

Because of the principles of grounded theory methods, the literature review was compiled after I had already collected a majority of my qualitative research and was fully ingrained into the transcribing, coding, and analyzing of my participants' qualitative answers to the survey and interview questions.

Kathy Charmaz, sociology professor and director of Sonoma State University's Faculty Writing Program, states that, "Grounded theory methods consist of systematic, yet flexible guidelines for collecting and analyzing qualitative data to construct theories from the data themselves. Thus researchers construct a theory 'grounded' in their data...Ground theory methods lead you to make early stops to analyze what you find along your path.” (1). In a somewhat ironic way, my own enjoyment of analyzing the usage of structural assisting metatexts 
perfectly connects with the employment of ground theory in a study about them. By using grounded theory methods, I allowed myself the agency to adjust definitions and components of my lists of codes as more and more data came in given the longitudinal length of my study. This relates to my literature review in that I did not feel as if I was wasting my time in guessing or hoping certain concepts in pieces of scholarly work that I loved, or were strongly connected to as an educator, would come up in the data my student participants gave me if I had done the literature prior to any data collection or participant recruitment. Rather, I had a working knowledge of what educational, agency, and human interaction based areas I wanted to include as truly relevant information to precede my readers' thoughts and understandings of my own connected data analyses and applications. The following pieces of scholarly writing are what I either found as a result of, or was able to maintain based on applying my data/analysis to said data to the pieces of literature I would include or read about thanks to having a grounded theory framework.

\section{Writer's Memo Related}

Further providing evidence for the lack of scholarly work with the education community was the fact that of the two published texts I found explicitly studying the usage of some variation of a Writer's Memo, both were focused on using their memos as a form of communication between just the student writer and their instructor. In my classes, as well as Dr. Broad's classes described in this study's introduction, our memos are involved directly in peer to peer communications for an 'in process' draft, that has yet to be turned in for a final grade. The instructors will still read and acknowledge the Writer's Memo in some way, but the core audience of these memos are the peers of the writer rather than their mentors or instructors. 
However, these differences in use did not mean there were no areas of common ground or areas of consideration when looking at related concepts surrounding revision, writer to reader communication, and the value prescribed to this kind of structural assisting metatext.

Jeffrey Sommers, while serving as the inspiration behind my first exposure to the Writer's Memo, has his own set of beliefs and styles regarding his 'Student-Teacher Memo'. In his article, published in a 1988 issue of College Composition and Communication, Sommers feels this kind of structural assisting metatext is an excellent answer to the concerns of many process-orientated FYC course teachers. These concerns were proactively considered, as he frequently established the purpose to his readers in the same way he would to the classes the memo is used.

The high level of justification shown by Sommers to his students is a core element of why I believe these kinds of metatexts appear to be so effective in the scholarly work that is out there about them. It acts as a way to provide focus, purpose, and clarity, while also allowing for variation in which they are used. He further states that the core questions (four total) within the memo can change depending on the type of writing being crafted. This shows his clear understanding for different kinds of writing needing adjustments either in what the writer writes in a memo, or how the memo is structured for the writer to get the most out of the peer responses they receive. Specifically, the areas of the Student-Teacher Memo that do not change draft to draft involve, student reflections on journal entries, the part of the draft they feel is the most successful, the part(s) of the draft they feel warrant comments. While my own memos don't change their structure or questions depending on the genre/type of writing being completed, the variation and acknowledgement of writer individuality is kept at the forefront of the existence of the Writer's Memo and Proposal. 
Similarly, the previously mentioned work of Anthony Bryan Bardine and Anthony Fulton closely fit Sommers own memo framework. But their classrooms call them 'Revision Memos' as the emphasis is on taking the feedback from readers and conscious reflection on why certain revisions were made draft to draft of a text's life. Though the reasoning for this additional resource is slightly adjusted from just writer to reader communication, the memo's ability to help develop a written text and a writer's reflective abilities are still at the forefront of this kind of structural assisting metatext, "To overcome most challenges, teachers must clearly state the purpose and rationale for all self-reflective writing, implement collaborative learning, clarify the audience, and tailor assignments to promote self-development" (150). This promotion of selfimprovement with structural guidance from an instructor is what appears to make this kind of task so beneficial to Bardine and Fulton's classrooms. Utilizing the comments from their instructors for the revision of said draft based on the Revision Memo, it appears to have a further communicative nature between writer and reader, "because of the structure of the revision memos, she (a student of one of the authors) is reading the comments written on her papers, something many students fail to do, and using them to improve future drafts." (151). Again, every action involving this fully functional metatext is clearly tied to tangible benefits to the student writer that can easily be applied to their current project rather than unstructured peer/instructor feedback experiences for novice writers or those that have not deeply studied composition related theory.

Furthermore, Sommers's structure of these memos are meant to help guide students to consider multiple areas of their written work instead of a wholistic view that many nonorganized reflections and peer review days suffer from: 
I also use these questions at times to suggest writing approaches; by asking 'which part do you think will need revision?' I can suggest that most writing only becomes effective after the writer has rewritten it. When students are asked to identify the best part of their papers, they infer that there is, in fact, something good in the paper-a feeling that can lessen writing anxiety. (79).

By 'forcing' the different kinds of people that enter the writing classroom to talk about their own writing and ideas in a way that might be a way in which they don't typically talk about their work, or an area they don't see as a strong component of their abilities, it can hopefully open new perspectives to how they self-assess their own projects and quality of their creations. Sommers' valuing of this kind of atypical requirement for composition students is adjusted, while still having the same focus of forcing students to look at different aspects of their work, is also shared by Bardine and Fulton:

The revision strategies that student writers impose on themselves continue to be a concern of process-orientated teaching in the composition classroom. Researchers have examined a variety of approaches including how unskilled and experienced writers revise their writing (Berkenkotter, Perl, Sommers)...Revision memos are written documents student writers complete after they revise a piece of writing. When writing revision memos, students detail the strengths and weaknesses they see in the new draft (149).

When left to their own devices, there is no way for educators to guarantee that students are meeting the learning outcomes of their course as well as being conscious creators of their own products. This isn't to say any of these scholars, and myself, feel that our students are incapable of doing it on their own. But it allows the entire classroom community to partake in similar writing practices and better understand the respective minds that created the draft being 
reviewed. Bardine and Fulton feel that the memos are just as important to those reviewing the work as the original writer of the text:

Both authors (Bardine and Fulton) used the memos to help students reflect on their writing and continue revising. The memos also served as guides for the instructors as they responded to their students' writing. The memos were a reminder that the instructors needed to focus their commentary so that the students would be able to revise more effectively. (149).

This open forum of communication gives an added layer of context to a text (the draft being reviewed) that would otherwise typically operate in isolation, with the addition of a structural assisting metatext, the Writer's Memo. Because these concepts are often foreign to students, presenting examples of finished products of the memo is a point of emphasis in Sommers's classroom, he shows the openness needed to truly get the most out of reflective experiences where a writer communicates with others about their own work, rather than going into the task of deep reflections of one's own writing blindly, he offers his own written examples of the memo and accompanying drafts, "My purpose was to offer a model for their memos-a model in terms of length, depth, and honesty of response since I had confessed to doubts and difficulties in writing" (79). The core of a successful memo-using classroom appears to be, at least in Sommers's case, the consistent description of purpose while embracing the individuality of the memo writing and the human beings that write them.

\section{Reader Feedback for Writing Completed in Non-FYC Courses}

Given my hopes for the far reaching impact of my study and accompanying research, my framework in the world of education had to include work completed in non-American academic 
settings. Not only this, but I wanted to see the ways feedback was/is being utilized in courses beyond composition or any other English subcategory. Thankfully, I was able to find three published studies that had one or both of these aspects involved. However, I cannot accurately guess the impact these non-American and non-English classroom applications of feedback had if they were completed in a location/classroom like American higher education FYC courses. But I am confident that several of the apparent themes within each of this studies, including the importance of perceived effort a person feels the other has given to their work, the necessity of explicit instruction of how to/ways to assess another's work, and how to dig deeper than surfacelevel evaluative feedback, are also apparent in my own research's findings and analysis chapters found later on in this study.

Firstly, within the ecology program at the University of Otago in Dunedin, New Zealand, several researchers at the university, including Tony Harland, were curious about the benefits of reader review on scientific kinds of writing. For their study, they zoned in on student researchers' usage of reader feedback when writing practice grant research proposals in the field of science. Directly related to how the feedback was used, the scholars were also interested on if students writers felt they were able to understand the process of reader review as well as the structure of the feedback they received within program concepts of feedback (802). Because of the educators' value of the potential difference between the experience a writer has viewing the commentary on their work from different types of readers, the practice grant proposals went through an anonymous panel discussion of both peers of the writer and teachers within the department. The students could also add their own commentary to counteract the words of their readers with what they coined as a 'rebuttal' (803). To further this data, Harland and his 
colleagues had several of their students participate in semi-structured interviews to share their findings.

What appeared to be the most interesting aspect of their study was what the scholars believed to be the biggest factor impacting how seriously the student writer took the remarks, the prescribed merit (or quality) the writer gave to the feedback their grant proposal received. This factor transcended whether or not a reader's feedback was more praise oriented or more constructively critical:

Despite students claiming they could tell if the reviewer was a teacher or student, this was not always the case, and both student and teacher feedback was accepted on merit. Analysis of feedback types and rebuttal actions showed similar patterns between students and teachers. Where teachers differed slightly was in the use of questions and giving direction. (801).

Calling back to the usage of metatexts by Sommers, and Bardine and Fulton, the experience factor of teachers giving different kinds of suggestions or remarks in regards to guidance and thought provoking questions could very well be a reason why these were the only major differences in the types and amounts of feedback the readers gave the proposal grant writer. Because the proposal grant feedback was formative, meaning it was purely for practice and revision in the writing process before potentially submitting it outside of the classroom, the researchers felt that there were several positives of these activities in this non-English course environment:

A number of benefits are known to derive from such an approach (to getting formative feedback on scientific proposals)... developing analytical skills, clarification of the required level of work, increasing students' levels of responsibility and involvement, and 
enhancing learning and confidence... Students develop analytical ability from first evaluating knowledge, and then through the process of giving and receiving criticism. It is clear that feedback is most effective when students are actively involved in the process (Harland et al. 802).

This participatory role in receiving, as well as giving, feedback was not present in the scholars that utilized memo-based metatexts in this chapter's prior subsection. When this reciprocal approach is used, the benefits are arguably more powerful than if students merely took on one of the two roles involved in writer-reader communications. This isn't to say that the University of Otago based scholars merely threw their students to the wolves in terms of giving peer feedback, the writing environment was more so based on the structure of the grant proposal and the fact based writing that accompanied it, "The framework corresponded with the general guidelines for peer review: referential comments address editorial issues, how arguments are organised, theoretical and factual content and study design. Directive comments are concerned with giving suggestions for improvement, raising questions about the work and direct instructions for change." (803). Therefore, while the grant proposal operated as a sole entity without the benefit of a structural assisting metatext, the structure came into play in regard to how the responders gave feedback for the ease of the writer when reading multiple perspectives beyond their own.

The good and bad of this structuring of feedback, according to the researchers, comes down to whether or not the experiences made the students feel more qualified to give reviews to the work of another in a similar genre to what they have also written. This university is focused on the transfer of these in class experiences beyond a singular practice session, as, "The ecology programme is designed on the premise that, because students understand that the review exercise 
emulates a professional academic task, this will help them recognise the importance of the process and its potential for learning and improving work." (802). To their elation, the students whole-heartedly gained 'something' from the classroom grant proposal project and communication with other ecology students and teachers:

Students clearly valued the experience of peer review and had learned much from the exercise. However, even at the end of second year, they still felt like novices. They were concerned about not having enough specific subject expertise when each research project was in a unique area of ecology, and not directly related to their own knowledge. (806). This calls back to the entire purpose of structural assisting metatexts serving as sort of an 'requirement' or 'forcing' the student writers to look at their work through various lenses, often changing their language and practice in regards to how they self-reflect about their work and how their readers will react to the in-progress version of the main piece, it is intriguing to see that students taking on writer and reviewer roles did not feel like they were wasting their time in either action given the long term implications these kinds of roles and projects can have for even non-English classroom settings.

A student writing assessment study, this time working within the Netherlandic Utrecht University’s history department, was completed by Ineke van den Berg and other Utrecht researchers. Through analyzing the work within seven classrooms ranging from first year courses on historical research, to upperclassmen specialization courses such as writing for newspapers or biographies (138). Students were asked to assess their peers via the same criteria that their teachers would assess the final drafts on; with the scholars firmly believing that assessment being completed at multiple stages of the writing process would be best practice, "we suggest that feedback is adequate when (1) peer assessment has a summative (on the basis of a writing 
product) as well as a formative character (during the writing process); (2) the assessment is performed in small feedback groups; (3) the written feedback is orally explained and discussed with the receiver." (135). Similarly, each of these three traits in van den Berg et al.'s statement can be found in either one, or both, of my study's structural assisting metatexts. Further adding to this chapter's opening remarks about finding a noticeable lack in scholarship featuring the usage of structural assisting metatexts, the Netherlandic researchers felt that, at least in the article's publication in 2006:

Little is known about the content of students' feedback in educational designs employing PA (peer assessment). More insight into the nature of the feedback would indicate more clearly how students could support one another and what kind of assistance teachers should preferably provide. For example, teachers facing adequate feedback on style and appeal, but not on textual coherence or content, will know where to direct their assistance. (135-136).

Within this quote, it appears that the scholars are demanding more inquiry into the depths of what focused feedback. Primarily, studies about focused feedback about the reader's ability to understand the messages presented within the draft being commented on. Ultimately, the educators felt that a lack of formal training in what they should assess within a draft, as well as how to assess another's writing, hurt the quality and depth of what the history students could do with the feedback their works received. Which adds more fuel to my hopefulness of my study to be a resource for having students appreciate the writing process and describe their own processes to others:

...it is hardly surprising to conclude that, generally, students' feedback was mainly evaluative in nature. After all, the task instruction was to assess someone else's writing 
product. Another explanation for students not addressing the writing process is, to our opinion, the fact that most of them were not used to receive process-oriented feedback from the teacher, so they had no model. If we had wanted students to comment not only on products, but also on the working process, they had to be trained to do so. (van den Berg et al. 145).

An even less beneficial and more critical study featuring reader feedback was described at Oxford Brookes University within the United Kingdom. Wherein several scholars including Margaret Price, established a three year study took place to learn how to engage business students more effectively with assessment feedback. Where the data was collected through semistructured interviews and questionnaires with staff and students (280-281).

Once again offering a different framework than the ecology, history, and English classroom settings described in the preceding texts. Here, each piece of feedback is viewed as fitting in one of five purposes or correction, their terminology for assessment. These five areas were listed as reinforcement, forensic diagnosis, benchmarking, and longitudinal development (278). Which I immediately felt uneasy about given the apparent lack of student agency within 'where' feedback falls under or 'what' it can do for a draft being reviewed. This is extremely different than the structural assisting metatexts I use in my own classes, wherein my students use their own interpretations of what they feel is a good project topic and what they need from their peers and instructor to succeed on the assignment (via the Proposal). It also differs from the more structured of the two metatexts in my own study (via the Writer's Memo) by having much tighter boxes on what is and isn't one of feedback's five purposes of feedback. In a Writer's Memo, a strength to one writer could be another's biggest concern, or their description of the process 
might be more detailed and elaborate than a student who feels that a less structured and outlined writing style fits them the best.

As my immediate assumptions of the numerous purposes of feedback suggested, issues became apparent based on the multiple interpretations student writers had of where to place pieces of feedback.

Difficulties relating to multiple purposes of feedback, its temporal nature and the capabilities of evaluators reveal that measuring effectiveness is fraught with difficulty. The paper argues that the learner is in the best position to judge the effectiveness of feedback, but may not always recognise the benefits it provides. Therefore, the pedagogic literacy of students is key to evaluation of feedback and feedback processes. (277). While it is interesting to note that the educators feel that the student/learner is the best judge of feedback, their inexperience with layered usages and interpretations of various readers' responses mirrors the lacking confidence felt by Harland and his peers within their study of ecology students' proposal grants in the preceding analyzed study. It seems that a lesser amount of structural assistance, (with the Harland piece) or a too strict labeling of structural assistance (with Price and her peers) has somewhat of a correlation with the positive feelings and results of writer-reader review and communications.

While even a small amount of variance via agency is inevitable even with the stricter purposes of feedback outlined within the business courses the study took place within, the researchers argued that, "feedback is provided as part of an assessment process that uses both partially explicated criteria and professional judgement (O’Donovan, Price, and Rust 2008). This leads to an inevitable lack of clarity of assessment standards and therefore the potential for ambiguity in the giving, receiving and interpretation of feedback." (278). Therefore, it appears 
that the researchers are shifting the 'blame' of less than desirable utilizations of their five feedback purpose groupings on the students not understanding the feedback aspects written by outsiders to the individualized writing process the student writer is currently experiencing. Instead, what makes the usage of structural assisting metatexts that encourage a more balanced mix of guidelines and agency offers the students a chance to create their own goals and rise to the challenge rather than having a universally defined challenge based on the beliefs of outsiders who surely have more experience in writing far more advanced pieces of text.

What's even more disheartening about the boxing in of feedback's purposes is that it did little to lessen the issues with understanding feedback among the student writers, as qualitative data collected in the study shows, "The interview data illustrated a high level of confusion over the purpose of feedback among, and between, staff and students. Beliefs around purpose ranged from correction to longitudinal development in both staff and student groups," (283). The barriers of feedback outlined at the start of their study appear to have more harm than benefit when the business students engaged in peer review. Further showing the need for adjustments in regards to who sets up the qualifications of what pieces of feedback can mean, and how they can be utilized by a writer or reader.

In all three of these non-American and non-English Language Arts classroom instances of reader feedback, the core issue was not that students did not see benefits of the experiences for their writing in a sometimes atypical writing environment; rather, the framework within which their writing processes were operating within was either too restricting or not providing enough guidance for student writers compared to other classrooms utilizing well thought out and explained resources, like Sommers, and Bardine and Fulton, that clearly outlined purposes of their structural assisting metatexts, while also showing a defined value for writer variance in how 
they made use of the different components of their memos. One can argue that these pedagogical actions are even more important in non-English classroom settings, especially when it can be reasonably expected that less writing practice will occur than what takes place in literature or composition focused courses.

\section{The Acknowledgement of Web Based Courses}

Beyond differentiation that exists within the subject area, the extensive employment of technology, to the point of the class being entirely online was not something I had originally thought about in the early stages of my research and methods formulations. Despite being an educator that strongly prefers in person classes for at least part of any kind of instruction or discussion, it is not fair to completely ignore the prevalence and need to consider online based courses. As they too are fully capable of successfully having peer assessment and structurally assisted agency in their virtual environments.

Yao-Ting Sung and multiple educators at National Taiwan University had setup student reflection and feedback components within a particular psychology course, to be entirely online. In accordance with allowing more student agency in their topic selection/structuring of the respective draft, while working within the relatively short time period that a singular course allows for, the instructors believed that "An alternative to doing a complete study is to have students write a research proposal. Writing proposals has many of the advantages of implementing projects, and because proposals are free of the constraints of execution, students may be more creative..." (331). This form of a proposal, is similar to the grant proposals outlined in the Harland et al. study within their university's ecology department. Meaning that their usage of the term 'proposal' is very different than the kind of text I use the term with. 
Within the psychology program, a quick overview of the study revealed that, "Thirty-four undergraduates used Web-based self- and peer-assessment procedures for evaluating proposals in experimental psychology courses. Students presented their proposals and commented on the proposals of others on the Web. Results indicated that proposal observation and peer interaction enhanced the quality of students' proposals." (331). Certainly, I was not surprised by the positive impact student agency and the helpful commentary of their peers was found to be beneficial by the student writers. What did confuse me though, was that the lack of face-to-face interaction not being preferred or requested by the students. Could it be that because these students knew, and therefore preferred, that the course was done in an online format? Does it indicate that any form of audience feedback, no matter the mode and focus, is better than no 'in process' feedback? I hope that, with the multitude of genres that received feedback in my study, that these questions will have some more clarity at the conclusion of my own data's analysis.

What did have clearly stated beliefs from the scholars at the end of their writings, is that the largest changes, as a result of receiving feedback on their original projects, were students that had the lowest overall grades in the course at the time of receiving said commentary, "Our study also found that groups with lower grades revised their assessment in a more exaggerated way after observing the evaluation results of all groups." (Sung et al. 334). Allowing further optimism for myself in the potential applicability of structural assisting metatexts to students of all ability levels and prior academic experiences. And, even as someone who will still cautiously back away from online centered courses, it gives me confidence to see the effectiveness of a ‘technology screen only' self/peer assessment format. 


\section{Effort and Agency in Students Related}

The writing/creation process for any person is often highly individualized no matter the level of structure the writer/creator is tasked with working under in academic, professional, or casual circumstances. Every aspect of the writing process could be argued as being just as dependent on whether or not the writer (especially if they are student writers) is putting in a satisfactory amount of effort, care, or passion into their work to meet the requirements set for them, or set by themselves.

Sadly, as alluded to in the introduction of this thesis, there is a lack of studies that center on 'effort' and its connection to the work that students complete in educational environments as a whole, not just in composition based classrooms. The same study that this quote was pulled from decided to break away from the norms of empirical research and actively involve those actively or passively involved in 'seeing' the amount of effort put in by students on academic endeavors. While this particular study, completed by several researchers at multiple universities, including Andrew Stables, took place in Great Britain it became very apparent that the understandings and values of effort can relate to nearly every academic setting. The title of the article itself, 'Concepts of effort among students, teachers, and parents within an English secondary school' gives a great deal of context regarding the kinds of people the study was concerned about.

The scholars based their findings on a combination of focus groups of these three types of people and a literature review of the limited resources concerning the study of effort in school settings. Unsurprisingly, the research found that conceptualizations of effort were highly variable and layered: 
The assessment of effort, alongside that of achievement, remains widespread...Analysis reveals that understandings of 'effort' are not uniform. Rather, 'effort' is a shorthand term, which can be used variably, therefore can be construed as a tool of negotiation, or a form of investment in a set of aims distinctive to each group or individual case... There is a strong case for more sustained research into the operationalizing of such key concepts in schools and other professional and workplace settings. (626).

The transfer of a study on effort within students on the understandings of the term in adult workplaces is very jarring given the consistently emphasized need for more kinds of research in the article, especially for a study published in 2014. The psychology behind these findings and lack of consistent understandings of what quality effort on schoolwork looks like was later inferred to the supporting element of a student's 'arousal' with the task at hand, "There is an obvious educational implication here. However committed the student is, she will only be able to rouse herself fully in response to challenging demands and opportunities; we do not find it easy to work harder at boring tasks." (629). Yes, this statement might come off as obvious for anyone with teaching experience, that students aren't as readily willing or able to give as much hard work at uninteresting forms of assessment to them. But it calls back to the importance of agency that takes places within structural assisting metatexts that allows students to do their best to help make their assignments, and the activities it takes to complete them, much more valuable to them as they are tailoring the kinds of interactions that will occur within them.

This heightened understanding students have within the classroom, even if the ones in the focus groups were secondary school aged (middle school to high school aged in America) is telling in terms of how educators should balance structure and agency to get the most effort out of their students. Stables and his colleagues found that students were also aware of how to best 
utilize their time and care when giving any sort of effort, "Both quantitative and qualitative responses indicate that students are aware of the importance of making an effort as a general concept, but that in specific instances, such as homework, they feel they can choose where to bestow their effort." (634). As a result, not only does a student's interest in the work at hand impact the effort they give to a task, but also their opinions of when they feel is the best time to give a certain amount of their energy based upon how an assessment is framed. Like the term of 'effort' it's safe to assume that the same level of variance in conceptualization would exist if studies were done on the word, 'homework'.

Because process oriented pedagogies exist within many first year composition courses, the end products of units are a result of far more than just a well written assignment sheet and assuming that each student will have an easy understanding of how to best utilize their ideas and opinions within a framework that may or may not encourage their agency at each stage of the writing process. The article refers to this process in a standard K-12 environment around the image of a 'virtuous circle', wherein, “students consider they make more effort when they are having fun, and see effort as an element in a 'virtuous circle', comprising enjoyable lessons, interesting work, a sense of achievement and work for which there is an obvious point or purpose" (643). This 'point or purpose' is highly prioritized by those that have successfully utilized not only structural assisting metatexts, but communicative activities and assessments. For students can have increased success in seeing and comprehending the benefits of an activity if the purpose is emphasized and the students are involved in the adjusting of said activity to best 'fit' the desired purpose and outcome; thus, the best chance of maximum effort with ease. As Sommers and Bardine and Fulton do with their variations of the Writer's Memo, and successful 
implementations of peer review do when they involve students as both writers and reviewers of writing, rather than passive gears in a one size fits all machine.

\section{Writing Assessment/Assessment in General Related}

To fully understand the scope of why structural assisting metatexts within a student's writing process have great value, as well as warranting more research centered around them, a brief large scale view of the levels of agency allowed and trust within writing program (which first year composition courses fall under) have for their instructors and students. Renowned composition studies scholar Peter Elbow brings into question whether or not assessment and evaluation are always needed, in addition to what kinds of feedback are the most worthwhile for the classroom. While it can be hard for process oriented composition classes to find a singular answer, Elbow helps to narrow this down by showing the kind of feedback that does not fit the kinds of work done in composition classrooms:

A single number can never accurately represent the quality or value of a multidimensional entity and writing is inherently multidimensional... No single number will do. Even if one reader thinks that all the dimensions of a piece are of equal value (e.g. B minus) some other reader will weight the dimensions differently. (304).

Because composition instructors ask so much within the summative assessments their students submit, it is simply hypocritical to only give their work a singular number based on a singular person's opinion on criteria of what 'quality' writing looks like for the assignment along with few if any supporting qualitative comments. Not only this, there's no telling how another reader will react and weight the same work even when given the same assignment sheet. The qualitative words that go along with a reader's letter or number grade, are what give that same 
quantitative letter or number grade the value and depth that our students deserve. Elbow agrees with this larger weight given to the qualitative comments on a piece of writing when he appears to give instructors an ultimatum, "If we accept the premise that writing is for human readers (rather than God or machine scoring devices), then the value of a piece of writing must be tied to the responses of human readers" (304). To separate themselves from scantron graders or other computerized assessors, humans need to back up their claims for a specific grade, with the responses that are paired with whatever letter or number grade the student has earned. Not because they need to show off their analytical abilities as the instructor of a class, but because it is the kind of work called upon by the type of effort students give in top-tier composition classrooms.

Along these lines, if we are giving a high amount of faith into the work that human readers are capable of when responding to student writing; that same belief in FYC instructors should be given to the design of these same courses that the writing is completed in. For example, the work done at Washington State University, where the assessment program involved multiple levels of input by expert consultants, but more importantly, instructor input. These layers of expert outsider and local insider input show the importance that:

No individual drives the process at any level; for the four years that students attend the university. They (students) move through a progressively challenging curriculum that is the turf of the instructors" (Elliot and Perelman 150). Where Diane Kelly-Riley proudly proclaims that her university, "is the only public institution to offer a curriculum-wide undergraduate Writing Program that combines university wide assessment, instruction, and faculty support throughout the entire undergraduate writing experience (160). 
This consistent faith in the quality of ideas given by the instructors within the department and across the university allows a collaboration that universities that follow everything by an outsiders book given to every composition instructor do not, and I'm sure the results side with the former's style of putting ownership in local decision makers (the teachers') hands.

Tying these concepts together to involve the students too, Louisiana State University allowed their students and instructors to work together to correct where incoming standardized test scores fail the incoming students' placement in FYC courses via a piece of technology, “iMOAT (which) allows students to respond to a complex writing task by engaging selected readings and composing their responses in a virtually untimed environment...At LSU, this system allows students to challenge their placements, determined initially by SAT Reasoning Test and ACT scores. With writing samples scored by instructors" (Elliot and Perelman 151). This builds on the precedent set by Washington State that the implementation of outside resources with local influence or decision makers allows for the best results for the situational issues that arise in each place of learning's writing program.

Simply put, this literature review on writer-reader feedback, agency, and the implementation of resources, shows that when each of these areas present value to student writers. Triumphantly, when all three are combined in the writing/creation process of accomplishing a given task or goal, it creates a chance for great success and growth among the human beings involved. As a result of this peeking into the observations of other scholars in various world locations and academic settings, I am able to confidently tell the readers of this thesis that all three will be successfully implemented in my own classroom setting for this very research. 


\section{CHAPTER III: RESEARCH CONTEXTS AND METHODS: THEORY GROUNDED IN PARTICIPANT REFLECTIONS AND INTERACTIONS WITH METATEXTS AND THEIR PEERS}

\section{My Methodological Framework Partners in This Study}

When trying to find a way to answer my research question of, 'How do first year composition students use, understand, and value forms of structural assisting metatexts during the writing/creation process?" I wanted to ensure that the opinions of first year composition students, and not their instructor who has a degree in English, were at the forefront of whatever the answer to the question would be. After all, the answer to the preceding question should not be based solely on the observations of writing studies scholars, as respecting the opinions and perspectives of the very writers utilizing the tools provided by a first year composition allows for effective, and well-rounded growth and adjustments of the very resources that have been used by diverse writers within every first year composition classroom. Not only this, but a longitudinal (over a semester's length) conversation with the student writers would be a valuable way in which to track the growth in applying the tools (structural assisting metatexts in my case) over multiple kinds of writing for their summative assessments.

As a result of these desires in the kind of data I was looking for to answer my research question, the research was conducted via two related methodologies of 'empirical qualitative research' as a whole, and a subset of this research, the previously mentioned grounded theory. Which thankfully, I had the pleasure of being exposed to through a composition studies graduate level course. For, as said by Charmaz, those that utilize ground theory, "construct a theory 'grounded' in their data" (1). This aligns excellently with my description of how I wanted to answer my research question, in that the emerging results and analyses are essentially 'home 
grown' within the data that was collected within the research study's setting. However, this is not to say that I am not optimistic about the implications of the analyses of said data in other settings, but to instead embrace the locality of the collected data in the great amount that it influences the resulting theories and future adjustments in related studies or composition courses I am a part of conducting.

Secondly, given my research question's emphasis on the students' perspectives during the writing/creating process, the other approach I ended up employing in my data collection and analysis was empirical-qualitative research. Bob Broad explains that, "The primary focus of the empirical-qualitative researcher is relationships and interactions among people, not published texts." (199). Despite the key tools involved in the study being structural assisting metatexts, I am more focused on the interactions that are either created or impacted by their utilization among first year composition students. These interactions were between the students and their peers, the students and the instructor, and each student's internal monologues.

Empirical-qualitative research answered another one of my concerns about categorizing and placing subsequent value on each piece of data in a study concerned with the interactions of people surrounded by written texts. Broad follows up with stating that these actions are done by an empirical qualitative researcher when they, "usefully and meaningfully separate out the context-freeing (objectivist, experimentalist, quantitative) from the context-preserving (interpretive, naturalistic, qualitative) methods of analysis, and among those using words as our chief kind of data, we distinguish the textual from the empirical.” (199). This separation technique perfectly pairs with the core beliefs of grounded theory, as the conclusions of the study are clearly organized and acknowledged as being based in the data rather than preconceived or clouded judgements from the researchers' prior experiences and/or the plentiful studies they 
might have read before working on their own methods and preliminary data collection. By my studied efforts to remain openminded and to seek alternative forms of interpretations, I was already actively working to integrate the methods of grounded theory in my own study and lack of initial hypotheses. What I did not realize at the time, was that I was also employing empiricalqualitative research methods on a larger scale in these attempts to remain openminded to any possible data results from my qualitative responses from my student participants.

In regard to how I ended up answering my final major data related concern, of placing value on my treasure trove of data, I had once again found myself ironically being an empiricalqualitative researcher. In his own study on what English instructors value from the work completed by their students, Broad, 'felt a powerful attraction to integrate 'live' conversations into what would otherwise be traditional textual research because I believed that distinctive and valuable kinds of knowledge were created in the interplay between the empirical and textual spheres" (203). Mirroring my own research desires, both of which involve the fascination with what other people, with varying experiences and beliefs on writing studies (and the specific concepts we were placing a higher level of interest on) are allowing our research to be as far reaching and well-rounded as possible. As empirical qualitative researchers, as well as those of us diving deeper into the related concept of grounded theory, we are attempting to be as open minded as possible with the responses that might occur when we allow the words and thought processes our participants concerning their interactions with one another to be honestly shared via open-ended research questions and data collection methods.

With these two added comrades to my own mind as a composition instructor, I felt much more at ease to dive into the deep end of data collection and analysis. Ground theory and empirical-qualitative research prompted and/or justified my usage of narrative qualities in my 
questions to my participants leading to the resulting theories, and how I involved and placed an extremely high amount of stock into the student participants that were involved in the study.

\section{Grounded Theory/Narratives in Writing and Research}

With any qualitative research, there is an opportunity to provide as much or as little context about our data as possible. In some projects, a table, bar graph, or even just reading and showing off statistics is enough for the researcher and audience depending on the questions and data being studied. Within research on writing specifically, giving our data and analyses a high amount of context gives it a story like feel, also known as a 'narrative'. Debra Journet, English professor at the University of Louisville, feels that this level of context is incredibly useful. Stating that, "Narrative' is a powerful word and concept in composition studies. As a discipline, we generally use narrative as both a mode of student writing (e.g., literary narrative or personal narrative) in which students construct stories of events or actions that are important to them, and as a research genre (e.g., case study or ethnography) in which the researcher represents her findings by telling a story.” (13). By the narrative approach I gave my collected data and the questions that prompted said remarks from my student participants, the data is deepened by the storytelling technique instead of just being a number of times a person says they agreed with or felt a certain emotion about the way a peer responded to their Writer's Memo or project draft it was paired with. To elaborate a bit more on the appeal of narrative within this study, grounded theory methods within empirical qualitative research want to place as much value on the responses our participants give us, and for my writing/creating process focus, the scenarios in which they recall their writing processes and interactions occurring. Journet appears to agree with this sentiment on situating the data for our audiences as for her own work, where "In each 
case, (student personal writing or research writing) narrative is valorized as a way of paying attention to the local and specific characteristics of experience, particularly as they are situated within social and cultural contexts." (13). Even with our shared feelings of the positives of narrative approaches, I cannot allow myself to wear blinders to the limitations of narrative approaches for over-glamorizing data to be something it either is not, producing results that can apply to every setting, or something we have no right to state as a fact concerning our discipline. I therefore want to acknowledge that, like Journet, I understand that this kind of narrative story telling approach to my data is, just like the data I gathered from five students in the same section of first year composition that I taught at Illinois State University's fall semester of 2019, is confined to the data I collected and my own analyses as a non-interviewee.

Beyond the time and place constraints of data, Journet declares that, "My argument is that composition research narratives of personal experience, rather than being inherently authentic, are also the product of genres: conventional stories we have learned to value as a discipline." (14). At this point in the study, I believe I have made it firmly clear the high place I have for narrative and large amounts of context in any kind of data. But by bringing these feelings and beliefs to the forefront here as the main researcher in this work, as well as analyzing the different kinds of work completed by my students throughout the class, as opposed to just one singular project; I hope to offer several counters or additional data to support my findings from said data as a whole.

What made discovering and constructing these data narratives in my research was having the ability to provide myself, as a teacher that already utilizes the structural assisting metatexts in their pedagogy, with multiple breakthrough moments in terms of how to better assist and employ these classroom resources of the Writer's Memo and Proposal for projects. In this case, my 
research truly fit what several co-author's, including Christina Haas, writing studies professor at the University of Minnesota, view as something just as valuable as the gaining of previously written scholarly knowledge on a topic, "While knowledge making is imperative for any disciplinary field...it is particularly important for the field of writing studies, where the object of study-contemporary writing practice-is not fixed but fluid and changing." (51). The everchanging practices and beliefs held by the stakeholders within writing studies for, no matter what the researcher already has expertise in, "Research is, in a very important way, learning what you don't already know. It requires putting oneself in an always uncomfortable position, a position of uncertainty." (53). Like myself, Haas and her co-researchers involved student participants in their research she documented, along with the previous quote, pieces of rationale

for these methods in a writing education focused study. While this is not a direct influence of the study as empirical qualitative research, narrative approaches, and grounded theory were to the study, it is quite relieving to see that vastly more experienced writing studies scholars feel similarly about the research within the field as worthwhile given the changing aspects around composition pedagogy.

\section{Involvement of Student Voices/Emphasis They are Given in This Study}

Building on the infusion of narrative qualities for added contextual detail in my data collection within a grounded theory as an empirical-qualitative researcher, my student participants were really the heart of the theory.

I was lucky enough to have seven students volunteer to be in the study, and narrowed the participants down to five after reading their initial survey answers for perspectives that were fairly different in terms of their background with their English courses, but also their feelings on 
peer review and the amount of agency they felt they had in their prior academic experiences. Additionally, all five students that ended up being involved in the full study wrote much more on their initial surveys than the remaining two that were not involved beyond the initial survey, and thus were not included in the data collection the study's theories built off of. For example, three of the seven original volunteers were overly positive about peer review and choice, but at times quite aware of the negative aspects that could be associated with it in certain scenarios, such as the perceived quality of their work from their peer reviewers. Whereas two of the seven that were also selected had either overly structured experiences or virtually no experience with peer review in their prior schooling. Given this, there were multiple perspectives being explored of the student volunteers. However, the final two volunteers, neither of which were selected for this incarnation of the study, did not have a strong opinion one way or the other about peer review and choice because of the length of time between their last academic experience (five years due to armed forces commitments) or their descriptions were shorter, quite vague, and uncertain in general. Which isn't to say that those two, or similar perspectives, wouldn't be worthwhile to pursue in future research of metatexts, agency, and peer review. The emphasis I placed on student voices is something Haas and her co-researchers also felt about a study concerning student voices where, "The intimate involvement of the students in the research meant that they were in a position to provide important insights on an almost daily basis." (57). While my participants and I only formally 'met' a handful of times about the study, they were working with their structural assisting metatexts throughout their major projects. Even from my reading of their initial survey answers, I was already feeling enlightened by the perspectives and thought processes each participant eloquently, but also honestly, described. 
To give a few more tangible scenarios of the three major kinds of perspectives found within the group of five student participants, one can look at their reflections towards their assessments on themselves utilizing agency as peer reviewers. A student going by the pseudonym of Leah shared her values overall by writing, "I am very respectful towards people in general...My intentions are always pure and I just want everyone to reach their fullest potential when writing." This kind of optimistic and good-intentioned actions mirror the sentiments felt by several of my educational colleagues. Yet, this is coming from a college freshmen student who I later learned was involved in AP courses and journalism throughout her years in high school. This sort of 'teacher mindset' held by a student was a positive outlook that I felt would be vital to bridge the gap between the words of first year composition students, and writing studies instructors/scholars. Two of my other participants also displayed similar optimistic/positive viewpoints on their prior school writing experiences, but Leah was by far the one that gave the most detail regarding the reasons for said optimism.

Conversely, a student with the pseudonym of Tracy felt that receiving feedback, while beneficial in some ways, was severely lacking in other areas due to being overly structured towards certain aspects of writing, "we (peer reviewers) really only helped with spelling, grammar, and mechanics. So they only got the surface value of my writing as opposed to the actual message." This understanding of the benefits and disadvantages of a mechanic's focused (or any) high school English course is the exact kind of multi-layered commentary that I would hope to find within a student written structural assisting metatext. Therefore, Tracy's perspective was one I desired to include in hopes of a having at least one participant that consistently looked at what they felt was the good and bad of each experience. 
The final major perspective that existed among the five students involved in the full study was held by a student using the pseudonym of Scotty. Scotty, while having long and multilayered responses to the initial survey, did not have the same amount of peer review or distinct encouragement with agency in terms of his writing process. He remarked that, 'I haven’t had much experience with peer review...It wasn't much but I would say it helped me appreciate others' work." This view contrasted with the vague and limited responses the two students that volunteered in the initial study, but were not included in the full study as Scotty still shows off his takeaways with his fairly minimal peer review and process focused writing structure presented. This provided a unique alternative perspective to the multi-layered and confident positions displayed in the reflections of Leah, Tracy, and the remaining two long term participants (Brian and Aspen) that were able to recall to justify their feelings towards peer review and the freedom they were allowed to exercise.

Another instance of previously published scholarly work intimately involving student participants, but on a co-researcher level, was completed by Angela Sheets, former graduate student at Illinois State University, used as a focus for her own Master's Thesis. The names, longitudinal projects, and specific quotes from her students were included in a her thesis, Waking Dormant Researchers: Student Co-Research as Writing Research Methodology and Pedagogy. Her core argument in this high amount of trust and value placed on the students' perspective was justified as, "From both a methodological and pedagogical perspective, I would argue that a coresearch model also has the potential to increase student investment in the investigation" (18). She spent several pages of her completed thesis describing the kinds of projects each of her coresearchers (the students) were completing. This did not come without a fair shake in analysis of their words and work by a more experienced writing studies scholar. Sheets gives the 
explanation of the process each piece of student work went through when included in her thesis work, "To better understand the writing that happened in the course, I created an overview of the student co-researchers' findings. I treated their final articles as scholarly literature and compiled their findings in chapter three of this thesis. Following each article summary, I evaluated the affordances and limitations of the findings" (34). Like Sheets, I gave the words of my participants more weight than typical survey or interview answers might, but they aren't without contextual information and analysis from a writing studies viewpoint and additional responses from their peers, or even other comments the person had made at different points in the study. While the students do not yet, if they ever will, have a Bachelor's degree or higher, the scenario of the study and the amount of writing and/or talking they added to the data made it impossible for Sheets, myself, and other scholars utilizing similar methods on emphasizing student input into pedagogical research even though they aren't as known or held in high regard by various fields at large.

The differences my study has with Sheets's is primarily from the scenarios of what we are studying. The students in Sheets's study were working on a singular project, while mine were working on three (one in each of the course's three units) very different types of writing. Given these differences, my data does not have a large chunk dedicated to describing each student. Instead, within each data collection breakdown there are descriptions of at least the overall feelings and reflections my five students gave for their prior experiences (the initial survey), each of our three FYC course units (the semi-structured interviews), and their feelings on the entire semester (the ending survey).

As I displayed previously with a few examples when justifying the five student participants' involvement in the full study, this is not to say that there won't be specific quotes or 
further elaboration on data and their subsequent codes, but the breakdowns of each student's perspectives and feelings are summarized so as not to overwhelm readers about knowing too much about the participants or the work completed in the course or prior academic settings. After all, the focus of this study is on the structural assisting metatexts used in the course, not on the kinds of songs, research articles, and personal narratives they completed in the three units.

\section{My Pedagogy Behind Sharing My Own Metatexts in FYC Courses}

Because structural assisting metatexts might be a new resource for some of the students in my classroom, let alone the two major ones students use in my courses while they are acting as writers of their own work (the Writer's Memo and Proposal), having samples of items made by their instructor outside of FYC felt like an essential part of these resources having the highest chance of success among the highest number of students I encounter.

What makes the non-FYC examples that are available are the settings and versions in which they were completed. I practiced a different version of the Writer's Memo (Figure 5) in an undergraduate advanced composition course, as well multiple graduate level courses concerning writing assessment and research methods within composition studies. On a similar note, I've written several proposals (Figure 6) for either conference presentations or publication opportunities within pedagogy and/or popular culture. Both of which are available as resources for my students and pointed out as ways I've attempted to make their own FYC work applicable to other settings. While these English major and education professional examples are paired with the examples I've made for my FYC students are set within different requirements of each respective metatext and audience, I do so with the desire of showing the transfer abilities these writing/creation processes have to their futures in and out of academia. In the previously 
mentioned study conducted by Harland and his peers, a long term impact of emphasizing active roles of back and forth communication between writers and their audiences was that "some students transferred their new peer review skills to help others outside of the ecology programme." (801). Which should be a goal of every FYC course as they are required for essentially every college major regardless of their career aspirations, and a core reason why the structural assisting distinctions of the metatexts used within my FYC courses are in place for hopefully an ease of transfer to other avenues students find themselves in.

Along these same lines, I am always sure to emphasize that a sample of the metatexts, or any major project that my students are assigned, is meant to be something that a finished product 'could' look like, not what it 'must' look like. As just like structural assisting metatexts, student agency and freedom of content is up to them so long as it fits the structural requirements of an assignment (such as word count, a certain number of examples, what kinds of traits are needed for a certain section).

Figure 5: Instructor's Sample WM from Their Own Undergrad To my wonderful ENG 246 classmates and Professor Broad,

1. As most of you already know, I work for ISU's football program as a student manager and the best "perk" of the job is probably traveling with the team to road games. With the only negative about these trips being the long hours spent driving to the universities or flying in airplanes. By the time ISU had made the playoffs this season it was bitterly cold in basically every part of the country as it was in the heart of the winter season. This caused many flight delays on trips due to ice/snow on the plane or on runways. The worst case of this was at Eastern Washington University where the flight was delayed over 2 hours; I know because I timed the delay on my iPod. I've never having been able to sleep on airplanes, so I decided to 
try multiple things with the people around me in order to pass the time and ended up having a great time on a cramped airplane despite already being up and on my feet for well over 14 hours. The motivation for writing this particular piece was to give a real scenario where waiting a long time for a flight could actually create some positive memories rather than simply sleeping it away like many of us do.

2. My favorite parts of this $\mathrm{CNF}$ would be my monologue on my reasoning for hating airplane bathrooms. I've been praised for my ranting ability and the mini-rant I give my readers a glimpse of that ability in this piece. I also enjoyed the scene discussing the silly activities we did to pass the time, specifically the UNO game and viewing the look-a-likes page that the EWU fans made for ISU's players and coaches.

3. I would like my readers to focus on the pacing of my piece, in particular is it easy for your mind to transition from one scene to the next? Because the entire CNF takes place in the same fairly small environment of the airplane I'm worried my transitions might be a little too vague and basic. Also, are the various forms of comedy used in the CNF easy to follow and do they make sense?

4. Because I generally don’t find myself going to comedy in my writing I decided to try something different with this piece and use comedy wherever possible given the context of trying to pass the time in a crappy situation. Overall any comments on the humor and flow of the piece would be greatly appreciated. -From Joey 
Figure 6: Instructor’s Sample Proposal for Completed Conference Presentation

\author{
Joey Dundovich \\ Creative Writing Education Today \\ Illinois Wesleyan University \\ October 10, 2018
}

Pushing the Boundaries of Constructive Criticism in Students

"I liked everything about this piece, I'm not sure what to suggest for improvement." "Maybe give more backstory? But it was great!" "This was good. You had some grammatical issues that's all. Then it's perfect."

I've heard these exact quotes, and variations of them, frequently during any discussion of a piece amongst classmates in college composition/creative writing courses and in my own career as an educator during peer review days where it is only two or three students discussing a paper. Each time, I've internally said, "These would be more beneficial if people weren't afraid of giving constructive criticism or the possible ramifications of not being totally positive and/or indifferent to a piece."

I believe, that if people openly discussed that giving constructive criticism when talking about someone's work that is in the room, then review sessions would be much more productive.

\title{
My Pedagogy Behind Practicing the Metatexts in FYC Courses
}

Before students first experience a Writer's Memo and Proposal for a major unit project, each component of these two metatexts are described and practiced either as an individual or within small groups.

In the case of the Writer's Memo, the first 'text' my students pair this with are themselves as writers and creators. Meaning that before they even engage with any substantial long term writing project, they have already reflected and analyzed their own prior writing experiences, their three biggest strengths as a writer, two or more areas of concern and focused feedback from their instructor in general, and forms of constructive criticism they might not desire or be comfortable with receiving at times in certain scenarios. This allows the student and their instructor to prepare for major projects as they have been forced into considering the 
student's self-awareness. Not to be one to against my own pedagogical beliefs, I too have made these 'self' Writer's Memos as an example but also to show my students my own assessment of my writing and creation of work. (Figure 7)

For the questions found within the Proposal, the 'textual scenarios' that are paired with this metatext are decisions and forms of discussion every person might engage with great frequency. Some sample scenarios include, deciding where to eat a meal, trying to persuade someone to allow you to live at a certain location, debating a car or form or transportation purchase, etc. By having these relatable scenarios as a starting point before students venture into the unknown and/or higher stake forms of writing for their unit projects, these practice sessions allow them to see the connections, just like the transfer work described by Harland and his peers, of the brainstorming stage in the writing process.

Figure 7: Instructor's Sample WM for Myself as a Writer

\section{What you did so far (describe your writing processes to this point). \\ 50 Words Minimum}

- As a writer, I've written a novel manuscript partially inspired by the closest thing I've had a relationship mixed with flashbacks of a younger, and even more awkward Joey. I've submitted a short story on the experiences and benefits of failure I've had a chapter published in a book on undergraduate enlightening experiences and in my college's academic journal on composition/the writing process.

- $\quad$ This semester, I'm working on writing my Master's thesis, which will be the first substantially long piece I'll have out in the world. (It's about Students' Uses, Understandings and Values from Metatext During the Peer Review and Proposal/Brainstorming portions of the writing/creation 


\begin{tabular}{|c|c|}
\hline & $\begin{array}{l}\text { process). I'm also considering } \\
\text { submitting another article to the } \\
\text { GWRJ (our class textbook that I } \\
\text { had something published in last } \\
\text { semester!) }\end{array}$ \\
\hline $\begin{array}{l}\text { 2. What you like about the current draft } \\
\text { (specific strength[s]) } \\
\text { Three Strengths } \\
45 \text { Words Total } \\
\text { Minimum }\end{array}$ & $\begin{array}{l}\text { - I love the amount of ideas I have } \\
\text { for works or things to adjust in my } \\
\text { current work related to teaching } \\
\text { and publication/presentations. } \\
\text { - I think I'm good at picking out } \\
\text { quotes from sources or creating } \\
\text { dialogue for more creative pieces. } \\
\text { Not that I don't like exposition or } \\
\text { explaining myself, but I enjoy } \\
\text { having dialogue in my work } \\
\text { (through fictional characters or real } \\
\text { people) } \\
\text { I take pride in my ability to read } \\
\text { and respond to others' works. } \\
\text { Providing feedback and engaging } \\
\text { in a discussion with the writer or } \\
\text { creator of a project is something I } \\
\text { truly value to help promote growth } \\
\text { and understanding for all involved. }\end{array}$ \\
\hline $\begin{array}{l}\text { 3. What you want from your readers (two } \\
\text { or three specific and well-developed } \\
\text { questions and/or points of focus) } \\
\text { Two or more Questions } \\
75 \text { Words Minimum. } \\
\text { Provide Specifics such } \\
\text { as Quotes, Pages, } \\
\text { and/or Paragraphs. }\end{array}$ & $\begin{array}{l}\text { I want to be intellectually } \\
\text { challenged by my classmates and } \\
\text { my students. Not by facts or } \\
\text { random pieces of data, but by their } \\
\text { own desires and ideas they have for } \\
\text { my respective goals, interests, and } \\
\text { lives. } \\
\text { - I want to receive honest and open } \\
\text { minded feedback from the readers } \\
\text { of my work, and the } \\
\text { activities/documents I provide my } \\
\text { students to help me improve as an } \\
\text { educator, mentor, and overall } \\
\text { person. }\end{array}$ \\
\hline
\end{tabular}




\begin{tabular}{|c|c|}
\hline & $\begin{array}{l}\text { I want genuine conversation from } \\
\text { those I encounter about why I } \\
\text { choose to do what I do. The } \\
\text { rationale or what drives my work, } \\
\text { my teaching, and me as a human } \\
\text { being navigating adulthood. }\end{array}$ \\
\hline $\begin{array}{l}\text { 4. No Go Zones (Things you don't want } \\
\text { constructive criticism on. No reason } \\
\text { required, but if you're comfortable } \\
\text { explaining why, I'm sure it would be } \\
\text { helpful (-) ) } \\
\text { YES/NO MINIMUM }\end{array}$ & $\begin{array}{l}\text { To my knowledge, nothing at the } \\
\text { moment in my CURRENT } \\
\text { projects. In the past, its been my } \\
\text { writings and experiences with } \\
\text { depression, Social Anxiety } \\
\text { Disorder, and my ups/downs in the } \\
\text { dating world. But, as it's hopefully } \\
\text { obvious to anyone I talk to, I'm } \\
\text { very open about talking about all of } \\
\text { those aspects of life at this point in } \\
\text { my life. }\end{array}$ \\
\hline
\end{tabular}

\section{Putting It All Together in My Note Taking and Data Grouping Practices}

How these narrative approaches based themselves from curiosity in my study, grounded theory, and empirical qualitative research manifested themselves within my data collection methods in the following ways.

A. Having two forms of data collection, those being two short answer surveys and three in person semi-structured interviews. The first survey was to understand each student participant's background with peer review, agency in school projects, and communications with others involved in the classroom (teachers and fellow students). This was followed by the three semistructed interviews focusing on each of the course's major summative assessments on different genres/types of writing and any growing trends I or the student noticed in their experiences for each respective point in the semester. The data collection ended with the final survey, with 
similar questions as the initial survey, but a reflection on their overall experiences on the now completed FYC course the study is based on.

B. Developing a list of codes. Which I defined as repeated words (and their synonyms) taken from the answers student participants had given when describing their feelings and experiences on the structural assisting metatexts and the communications that resulted from them. The ultimate list of codes is listed below in no particular order.

- Perspectives (Angles/Lenses/Opinions)

- Honest/Honesty

- Interest/Interested

- Content

- Grammar/Spelling

- Structure/Accountability

- Nitpick/Nitpicked/Nitpicking

- Constructive Criticism

- Discussion/Elaborate/Elaboration

- Confidence/Confident

- Caring/Passionate/Proud

- Purpose/Goals

- Process/Writer's Process

- Potential/Improvement 
C. Paired with the list of codes were specific breakdowns of how each coded word was used in connection to the type of data collection (survey or interview number) it came from, whether or not it was used in a positive or negative way, and what major topic theme (listed below) it most connected with when the code was used in a written/verbal student answer. The four major themes are topics of conversation and writing I noticed the students frequently bring up, but were not as specific as the preceding list of codes. As a result, the main purpose of the four major themes (and the positive or negative usage of them) was to help further separate and group the codes came from larger content trends, In my own notetaking and memos, the below structure is what it looked like without any of the quantitative data.

\section{- Structure/Accountability}

- Emotion Related Reactions

- Another Person Helping/Providing Guidance

- Prior Classroom Experiences

To wrap up the layout of my methodological breakdowns of my data, I wanted to place a full-fledged example taken directly from one of my five data collections. The bolded, numbered, and occasionally highlighted example below represents the first four codes and the results I gathered from the initial survey. With the coded word listed first, followed by total usage of the codes in that specific survey or interview, then further broken down into whether or not they were used positively or negatively, the number of times each code was used positively or negatively, ending with the number and kind of major theme the code fit into. 


\section{Excerpt of Specific Breakdowns for Initial Survey (Positive and Negative, Four Major}

\section{Themes)}

- Perspectives (Angles/Lenses/Opinions) 4 Total (2 Another Person, 2 Prior Exp)

- Grammar/Spelling 7 Total (1 Emotion, 6 Prior Exp)

Based on the above list of two of study's codes, student answers for the initial survey involving Grammar/Spelling occurred seven times. Within those seven occurrences, only one time was it used in a positive manner, and the other six times were viewed as negative experiences. The positive usage of Grammar/Spelling was used in an emotion based answer, such as Tracy's previously quoted remarks that all peer review consisted of in her high school was grammar, spelling, and mechanics at the expense of getting to the content of her papers. While all of the six negative usages of the code were mainly connected to their prior experiences, which also connects to Tracy's reflections.

However, as shown by the breakdowns in the positive usages of the Perspectives (Angles/Lenses/Opinions) code, the positive usages of it were sometimes centered around an interaction with another person, and sometimes focused on a prior experience. Leah's remarks about always having pure intentions when giving her feedback to people would then fit within the theme of 'another person' as this is something she believes she still holds today, compared to only/mostly utilizing it in her prior classroom experiences. While she doesn't flat out say one of the codes listed with 'perspectives' she is directly talking about how she approaches giving her style of feedback to other people's work. Which justifies it's fitting into the code of 'perspectives' as well as the code of 'potential/improvement' a word that she directly uses in the quote. 
With these added dimensions to a code, it became much easier for myself to give my data enough contextual information for both a longitudinal study over the work completed in a semester long FYC course, and the ability to notice specific trends with the kinds of writing and growing practice students utilized the structural assisting metatexts for.

\section{Methods Conclusion}

Because I used grounded theory, empirical-qualitative research, and narrative approaches in my methodology, my student participants were the real providers of data relevant to any theories I uncovered and/or analyzed. Even if I didn't use these practices, the limited literature relevant to structural assisting metatexts described in the prior chapter, and the more expansive literature in peer review in different situational contexts, would make coming up with hypotheses prior to gathering my own data a futile endeavor to apply to my own, and potentially others' educational environment.

The survey and interview question outlines I used for each of my five data collections are listed in the appendixes. And while they'll also come up in the following analysis chapters, having the time to reflect on my own reasons for my research methods, while also reading and considering the words of more experienced scholars and pedagogy theorists, boosted my confidence in the data collected, codes that emerged, and the concepts that resulted in my analyses. 
CHAPTER IV: ANALYSIS OF FINDINGS PART ONE: STUDENTS VALUE THE

APPARAENT CARE AND EFFORT A WRITER AND/OR PEER REVIEWER

GIVES AND THE DISCUSSIONS THAT SPARK FROM IT

\section{Overall Code List Elaboration and Intro to Takeaways Related to Common Codes Dealing with Interacting with Other People}

Due to the longitudinal length (the majority of a college semester) of my study, the early analyses of data centered around noticing trends among the answers of my five student participants in order to develop a list of recurring words and concepts (codes) they wrote or said. This is a process that Charmaz defines by feeling that "As grounded theorists, we study our early data and begin to separate, sort, and synthesize those data through qualitative coding. Coding means that we attach labels to segments of data that depict what each segment is about." (3). Through my early findings via my initial survey and first round of semi-structured interviews, I calculated 15 codes that I wanted to track in the long run. As shown by the ultimate list placed after this chapter introduction, a few of the 15 ended up occurring less than 10 times throughout the survey. Whether the word(s) were directly referred to by the participants, or if they were eluding to/making reference to the code, they were accounted for via several readings, quantitative calculations, and rereading/reconsidering based on what the later data collections revealed. As a result, my rationale for keeping the codes that came up less than 10 total times in my data collections is to acknowledge the early comments that caught my eye and to bolster the most common codes even more. My hope is that it can alleviate some of the contextual questions or concerns of readers to the depth of thought I gave to my coding for the entirety of the study. To expand, I didn't just abandon the code of 'Nitpick' or the code of 'Interest' because it hadn't reached double digits by my completion of coding the second set of semi-structured interviews in 
favor of codes that had already been accounted for several dozen times. I wanted to be sure to acknowledge and offer up this list of codes for future studies either I or a reader would want to replicate or study in a separate environment. Whether the differences in a research setting are the kinds of students, the descriptions and uses of the structural assisting metatexts, the summative assessments (or genres of writing) the metatexts are grouped with, and/or the academic setting within the English department and the university as a whole, I believe it serves as a way to further question and analyze how grounded theorists or other qualitative researchers review and consider their data.

Transitioning to the focus of this particular analysis chapter, I planned on covering the five most common of my codes in order to provide a sufficient scope of the participants' experiences with the metatexts and the activities associated with them. When analyzing what data is worthy of inclusion in a formal write up of a study, Charmaz believes that grounded theorists should ask themselves, "What kind of data stands as rich and sufficient? ... Have I gained multiple views of the participants range of actions? ... What kind of comparisons can I make between data?" (33). Thankfully, it became apparent that three of my five most common codes, Caring/Passionate/Proud, Discussion/Elaborate/Elaboration, and Perspectives (Angles/Lenses/Opinions) were all heavily influenced by the students' interactions with others either as writers or readers of the metatexts and corresponding drafts they were referring to in said metatext. By grouping these three common codes together for an overall analysis concerning the relationships and interactions of people, which is what Broad has called the primary focus of empirical-qualitative research (199), allowing the data and my subsequent commentary to paint a clear picture of helping to answer my primary research of question of, "How do first year 
composition students use, understand, and value forms of structural assisting metatexts during the writing/creation process?"

Not to be forgotten, the two remaining of the five most common codes (Structure/Accountability and Process/Writer's Process) will be paired together in chapter five of this study as they both deal more with the student writers' interactions with the format of the metatexts, themselves as individual writers/readers, and the actions they did to create their pieces of writing. This is not to say that there is a large boundary between the findings of chapter four and chapter five, but to allow the distinction of student writers' experiences with other human beings and the texts/their own thoughts to be given attention separately as well as together as shown by the answers my participants have given in the quotes that are abundant in these next two chapters.

Despite not being one of the metatexts emphasized in this study, the quotes from students make occasional reference to the 'Response Memo' which functions similarly to a Writer's Memo, but for those reading/peer reviewing a piece of writing with the structural assistance of a Writer's Memo. My reasoning for not including explicit questions or focuses on the Response Memo (Figure 8) in this study, despite the structural assistance it provides, is because it is dependent on additional variables that the Writer's Memo and Proposal are not influenced by. These include the writer they are reviewing, the amount of time and attention the writer gave to the draft being reviewed, and how the writer decides to answer the questions found within the Writer's Memo. As a result, the Response Memo was not paired with the two metatexts that this study followed. 
Figure 8: Response Memo (RM) Template

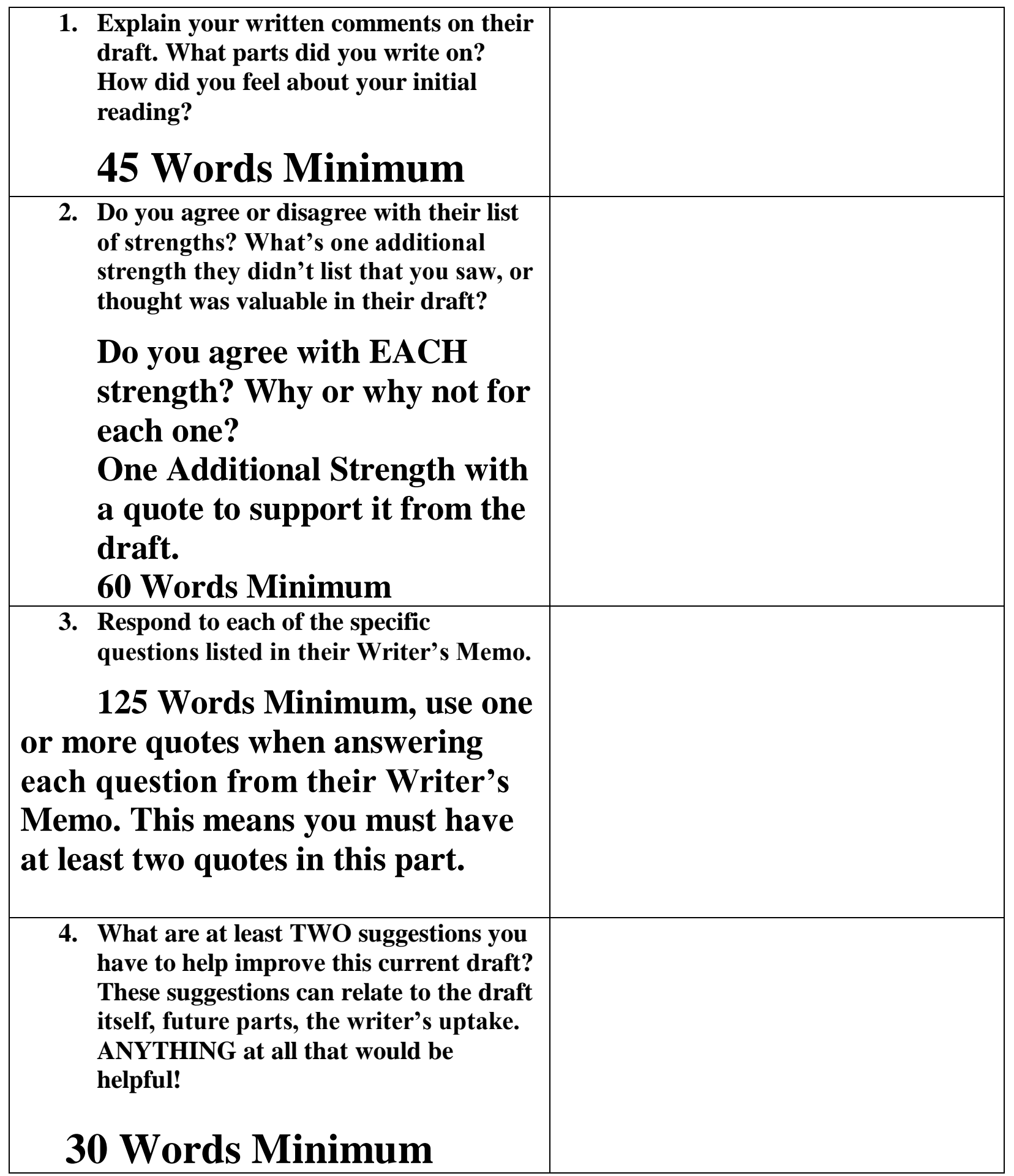


Cumulative Breakdowns for Entire Data Collection (Two Surveys, Three Interviews)

Note: An in depth walk through/description of my process in organizing my codes is given in the previous chapter on methods.

- Perspectives (Angles/Lenses/Opinions) - 58 times total

- Reflect/Thinking - 46 times total

- Honest/Honesty - 9 times total

- Interest/Interested - 3 times total

- Content - 53 times total

- Grammar/Spelling - 14 times total

- Structure/Accountability - 68 times total

- Nitpick/Nitpicked/Nitpicking - 1 times total

- Constructive Criticism - 10 times total

- Discussion/Elaborate/Elaboration - 61 times total

- Confidence/Confident - 40 times total

- Caring/Passionate/Proud - 87 times total

- Purpose/Goals - 23 times total

- Process/Writer's Process - 71 times total

- Potential/Improvement - 21 times total

Top 5 Codes Used

1.Caring/Passionate/Proud 87 times total

2.Process/Writer's Process 71 times total

3.Structure/Accountability 68 times total 


\section{Discussion/Elaborate/Elaboration 61 times total}

\section{Perspectives (Angles/Lenses/Opinions) 58 times total}

\section{The Code of Caring/Passionate/Proud Within the Effort Given and Received by Students}

- ' 'if you don't put in any effort or don't think about what you're asking, you're not gonna benefit from it." - Tracy

By far the most frequent code at 87 total uses and references, and something that I found myself immediately intrigued by in my initial survey analysis, was student participants saying/alluding to Caring/Passionate/Proud in their responses. In particular, virtually all of the negative remarks students gave to the lack of effort, time, and care by their peer reviewers and the weight their own ideas/remarks in prior academic settings was jarring to myself and the colleagues I shared my research work with. Which means that these experiences were before any of their introductions to either metatext in first-year composition. However, I believe it is still worthwhile to have a side by side comparison of a 'before and after' view that multiple students felt in the ending survey at the conclusion of their semester in FYC to their original thoughts entering the course.

A student, using the pseudonym of Leah, answered the initial survey question of, "If you had to describe what you think of when you hear peer review in ONE word prior to ENG 101, what would it be and why?" with the blunt statement of, "Yikes. Growing up I felt as if students didn't care enough to try to help each other out. I preferred receiving feedback from a teacher or parent instead because of this." It is also worthwhile to note that Leah still had a desire to receive feedback on her work from a person (such as a teacher or parent) that 'cared more' than her classmates to help her work improve for one reason or another. 
Quantifying or qualifying how much someone 'cares' of the amount of 'passion' and 'pride' they have in their work could be its own case study. Leah's trust in the level of 'care' a teacher or parent would put into commenting on their work potentially relates to the personal stake these two types of people have to her learning and growth compared to a typical classmate. The context and knowledge teachers and parents have available to them about their students could contribute to the reception of the feedback, and how likely it is that a reviewer would be further inclined to put more pride into helping the writer succeed and improve. To draw back to my reasoning for having a 'before and after' approach to the codes that appeared in the initial and ending survey, the term Leah associated with the level of care someone gave to her work adjusted as follows:

At the end of ENG 101, my word would be effort. Throughout this (peer review) you receive what you put into it. I spent a minimum of thirty minutes per person, therefore going in-depth during peer-review. I had classmates who did the same because they wanted to produce the best final product (like myself). My views have changed from my original 'yikes' and that is all because of your teaching style, thoroughness, and the tools (WM, Proposal ?s) we were given.

This 30 minute time frame is in reference to Leah's work in reading her peers' Writer's Memos and corresponding draft, and giving feedback in the form of written comments directly on the draft and a typed Response Memo. Given this context, the connection she makes between time, passion in working towards the best final product, and the metatexts (tools in her answer) contributed to her understanding that it knowing if/how much someone 'cares' when peer reviewing someone's work is a multilayered concept. However, with the right mindset, attention 
to detail, time put into the activity, and resources, a firm belief that a high level of care exists can be found in a writer's reflection of their work and/or the work of their peer reviewers.

The preceding aspects of the code 'Caring/Passionate/Proud' attributed to effort lends itself to the results of Tony Harland and his peers' study described in the literature review chapter. To briefly provide a reminder, Harland et al.'s work was with college students in an ecology program providing peer review feedback to grant proposals under the guidance of what they described as a great deal of structure and resource assistance in terms of how peer review would function within the ecology program and geared towards the genre of grant proposals. When summarizing their findings, the scholars believed that, "The study showed that, with good support and a highly structured process, undergraduate students were capable of providing a valuable contribution to peer learning and to their own educational experiences. Peer review helped them develop the ability to critically evaluate knowledge, which is an essential skill for all graduates.” (809). In the case of both studies (Harland et al.'s and my own) the feeling of assistance via textual structure and support from human beings is viewed as noteworthy in helping students get the most out of their writing experiences even if they are not English majors or planning on having a career as a writer or educator.

This realization of the role that putting your best foot forward and taking advantage of the resources given to you to increase your chances of success, as well as showing the care, passion, and pride you have in the task at hand was shared with Harland, his peers, Leah, and another one of my participants, going by the name of Tracy. After her first formal experience (described in the first semi-structured interview) with the Writer's Memo, Tracy came up with a conclusion regarding how to best use this metatext by saying: 
I see the Writer's Memo as, you get out of it what you put into it. So if you're asking the questions and putting things down that you want to know and you really want to improve your writing, then that's what you're gonna get out of it. But if you don't put in any effort or don't think about what you're asking, you're not gonna benefit from it.

Tracy's admission of needing to put in the work to truly gain the full potential of a resource correlates perfectly with the previous usage of 'effort' when describing peer review through the use of metatexts and thus is applicable to the larger code of caring/passionate/proud. It is apparent that these student writers believe that parents and teachers are assumed to have more experience than their classmates and have to these similar realizations of the benefits of giving effort and caring about a particular task within the writing/creating process. Conversely, if people are either ignorant or not willing to put in effort, and thus show that they care, then said resources will be pointless in the action for that particular person and activity.

Another dimension of the code caring/passionate/proud, which mainly occurred during the final data collections, was a feeling of connection between the writer and their audience or vice-versa and an investment from both parties involved in peer review to have the draft improved based on the reading of a draft's Writer's Memo.

When a student, going by the name of Brian, was asked about the impact his peers' Writer's Memos had when reviewing their work, he placed a great value on the context he learned through these metatexts by saying:

Theirs helped because they wrote about specific details in their paper that normally wouldn't stand out to a person reading their paper for the first time without any background or prior knowledge to it. So that's the stuff I kinda looked for, and when I found it I saw them in a new perspective and I have a better understanding of them when 
I read it. I don't know their experiences or what they've gone through, because I met them (his classmates) for the first time this year. And now that I read it, I feel like I got closer to them just from that.

This particular quote was taken from the third set of interviews, and was after a unit with the summative writing assignment being a piece of life writing on an experience that has made the writer a better communicator, writer, and/or person. So when Brian accurately described that he didn't know his peers' prior experiences, it's an honest statement on his ability to understand his peers' writing by just himself. This ability is assisted by the context in the Writer's Memo and allows the reader to feel a stronger connection to the writer and a feeling of a stronger sense of care when giving a draft feedback. Drawing a similarity between the prior descriptions of the code in this chapter of the people involved getting out of something what they put into it. If Brian felt he cared more about a peer's work because of their added effort in their draft's Writer's Memo, then his own effort in providing was improved as a result of the metatext on top of how much pride the writer took in using it to their benefit.

Building off of the participants', specifically Tracy's, correlation of 'you get what you give' out of using metatexts, she displayed a positive opinion when reflecting on the overall semester by believing that her memos (Writer's and Response) helped her peers as these metatexts, "provided them with my specific concerns that they could answer. We often talked about it in person but also about our content because it helped us learn about each other plus become closer friends." By pairing the content of the draft with the assessment and improvement based focuses within the memos, the groups Tracy was a part of during first-year composition felt more connected and personal than if peer review was not as structured as it was in the classroom. This means that her specific concerns about her, or a peer's, work could be given 
more care and attention because of the kinds of writing that are brought up when a draft is coupled with a metatext to provide context and the writer's explicit feelings on their current draft.

A noticeable feeling of a lack of effort and care given by a writer in the class was found by a student, going by the name of Scotty. Through the responses Scotty gave during the study, he routinely emphasized how he did not feel like he was a confident or 'good' writer. As a result, when a member of his third and final peer review group rushed through their work and in his words, 'clearly did not look over his Writer's Memo or the directions' Scotty felt that the feedback he could give could have larger scale impacts than normally. When asked a follow up question on the experience giving responses he gave the peer that did not display effort or care in his draft, Scotty responded by saying:

I guess, with the lack of effort it actually made it easier and I guess more enjoyable because I actually had something beneficial to bring to the table for them. And not so much of a, 'Hey this is good. Keep doing what you're doing.' I actually had content and, 'This is real. This is what you need to change. I get it, I was in the same boat as you, and here's how you can fix that.'

In this answer, Scotty quotes two potential avenues he could go down as a peer reviewer. The typical 'this is good' reply or the more caring and improvement orientated 'This is real. This is what you need to change... here's how you can fix that.' Whether Scotty's decision to give the longer, more time intensive response was based on the structural requirements (meeting the word counts and including direct quotes/references to the draft) of the Response Memo or not, he displayed an enjoyment of the opportunity to feel like he was making a tangible difference in how another's work would proceed. Despite his lack of confidence in his skills as a writer and 
reader compared to the other four participants, Scotty took a potentially fully negative experience with a peer and turned it into an opportunity for growth for himself and his peer with the assistance of the metatexts and his familiarity given that it was the third time using them in FYC.

This brings up the question of why the Proposal metatext was not brought up in this code's analysis, and on a larger scale, why it was not nearly as prevalently mentioned with student answers involving the Writer's Memo. I believe it has to do with the core audience of each of these metatexts. Because the Writer's Memo is written for the students' fellow student writers, there is more of a range/variety in the amount of effort shown by the two parties involved in the writing and reception of that metatext. In the case of the Proposal however, the instructor is the core audience of the student writer's thoughts and ideas associated with the larger piece of writing they are talking about. And, as evidenced by the comments about the kind of care and effort that a student writer expects from a teacher compared to their fellow students, less than a 'satisfactory' amount of care from these readers is not expected or experienced as much (if ever) according to the perspectives of the student writers in this study from work that is directed towards parents and teachers.

The core aspects of the code Caring/Passionate/Proud are correlated to the writer or reader's beliefs on the level of investment and time given to the activity, text, and most commonly, the audience of their/other's words. A direct connection between this valued connection (or lack thereof) between a person and one of these aspects is how becoming more invested can be aided by a metatext. The student participants feel that the context given by the writer on their draft and the structure of having to list their beliefs on the drafts strengths, their process writing it, and the desired areas of focus and feedback from their readers can allow for a higher level, or perceived level of care from a person involved in the peer review process. This 
provided context, is pushed further with the next code as the resulting conversations or added knowledge was viewed as beneficial as the reader and writer progressed in giving and receiving feedback through their main texts and the paired metatexts providing said context.

\section{The Code of Discussion/Elaborate/Elaboration to Create and Build on Understandings \\ - $\quad$ "it made it easier for me as the writer to ask for help on specific parts. As the reader it was very easy to be able to focus on the parts that needed help." - Aspen}

A code that was almost always directly tied to the follow up conversations that stemmed from the understandings and springboard opportunities from the questions being answered in a metatext was the uses/references to Discussion/Elaborate/Elaboration. It appeared that despite the extra 'work' that came with furthering written/verbal communication was viewed as beneficial overall instead of it being busy work or cliché compared to how some small group and one on one conversations can be in academic settings. The uses of this code were primarily used in reference to how a metatext prompted or added to discussions and elaborations. Basing themselves in the abilities for a writer to be explicit with what they want out of their project and the desired assistance from their peer reviewers and/or instructor, as well as the elaboration a reader feels they receive about the work and reasoning a writer put into the draft being reviewed.

A way these metatexts, specifically the Writer's Memo, benefitted future discussions and elaborations was displayed by how the student participants viewed getting their words out there on paper when referring to the main draft. Brian pictured this process as a practice session for later discussions by saying, "I feel like the Writer's Memo was sort of a draft for us to talk about (the main project) and then once we got to that face to face part then we already had that idea in our head and then we expanded on it once we got face to face." Additionally, a student going by 
the name of Aspen, echoed similar sentiments when reflecting on the overall semester, "During ENG 101 I always felt like my voice was heard. Not only did my peers and I communicate well overall but the Writer's/Response Memos allowed for us to get our thoughts and feelings/questions out. The Writer's Memo always came into play when we interacted face to face.” Brian and Aspen, despite being two of the most vocal, optimistic, and social students I have ever had as a teacher, placed a high amount of value on the work they put in to practice getting their 'thoughts and feelings/questions out' on paper before talking about them in person with others. This shows the potential diverse ways metatexts are taken up as not only a resource for the main piece of writing/ideas they are paired with, but also subsequent verbal conversations between the writer and their audience.

These connections and potential differences between written feedback and oral feedback provided with the help of a metatext (or any structurally assisting resources) were also found by Ineke van den Berg and other Dutch scholars at Utrecht University in the Netherlands. Their study, unlike my own research setting within just a first-year composition classroom, took place within the history department and centered on courses from first-year writing on historical research to upperclassmen specialization courses within the genres of newspapers and biographies (138). The study wanted to analyze written and oral peer feedback based on using the same assessment criteria (a rubric or rubric like materials) teachers used for final drafts of writing. Through their work, a difference in the content of these modes of feedback was evident as, "In their (history students') written feedback, students concentrated on evaluating the product, whereas oral feedback included more explanation and revision. Moreover, oral feedback also included more non-product-oriented feedback. If feedback on the writing process was provided at all, it was oral, rather than in written form.” (145). This contrasts with Brian and 
Aspen's views of metatexts (which provide written forms of feedback on a draft) as van den Berg et al. noticed a clear division between the kinds of topics covered in the two modes of explaining a person's assessment, whereas my student participants found written feedback to be an explorative space to prepare for elaboration when speaking to their peer review groups in person. Regardless, both the Dutch scholars and I have taken note of the benefit to having written feedback and orally spoken feedback as something more than just functioning as an echo chamber for the other.

Building off of her earlier appreciation for the space provided within the Writer's Memo to reflect and elaborate on her thoughts on a piece of writing, Aspen described how this metatext impacted her from both roles she took on in a peer review group:

In ENG 101 I had a very positive experience with the Writer's Memo. The major takeaway for me was being able to pinpoint the areas I wanted help with. I was able to get clarification on exactly what I asked about. These experiences were very beneficial because it made it easier for me as the writer to ask for help on specific parts. As the reader it was very easy to be able to focus on the parts that needed help.

Here, Aspen was essentially paraphrasing what my definition of a structural assisting metatext is in the introduction to this study, as a way to provide guidance and direction for all parties involved in writing and giving feedback on a project during various stages of the creation process. Again though, she placed value on having an 'easier' time in asking others for help on a project even though, at least in class, she was an ever present source of positivity and communication with myself and her classmates. And so, while I would have had full faith in Aspen's abilities to ask her peers for advice or feedback on her work and ideas, she felt it is worthwhile to have an added layer in the form of a metatext to ask others for their focused 
thoughts. Proving the potential for metatexts to impact even the most vocal of student writers to increase the kinds of reflections and descriptions they and their peer reviewers give to a draft.

To slightly shift gears to the benefits of how the reader interacts with the metatext and corresponding main text, the second set of interviews took place when finishing a unit with the summative piece of writing being a draft of a professional research article based on each student's major and how publications structured or talked about topics in each student's related career field. Meaning that, unless a group of students had exactly the same majors, the odds were extremely high that a writer's peer reviewers would have minimal background knowledge on the topics and worlds discussed in the draft. Because of this, Leah found herself appreciating the way a particular groupmate made a conscious effort to give her peers additional context in the Writer's Memo to help prepare her readers for the wildly unfamiliar content in the draft:

I think especially since there's varying majors within the students (in the class), and I had a girl in my group who was a nursing major, and I know nothing about nursing. And so reading her Writer's Memo kind of helped me get some background knowledge about what she was writing about and why she chose the topic she did. And otherwise I probably would've had my own assumptions of, 'Oh what does this mean?' or things like that... One of the girls that I read, in her Writer's Memo, explained how she answered questions so you didn't have to... if you were reading it (the draft) you might've asked yourself, 'Oh why is this like this?' and she would explain it right afterwards.

To mirror Leah's groupmate and provide some more elaboration on the piece being described, the writer spent time and space in her memo to define multiple tools and spaces that a nurse operates with and in. This meant that the student writer did not have to sacrifice space in her own draft, which was intended to be a professional research article, defining concepts to a 
hypothetical audience that she assumed would already know said concepts. Therefore, her elaboration in the Writer's Memo was intended to specifically help her peer reviewers as opposed to the ultimate target audience if she decides to pursue the project further in one of her major classes at college or for a professional publication. Thankfully, this proactive help provided to her readers (at least for Leah) improved the kind of feedback she could receive on her main draft.

To now formally introduce a quote emphasizing the second metatext involved in the study, the Proposal, which again takes place during the brainstorming/preliminary stages of deciding on an idea for a piece of writing/project, also found itself as an agent in promoting beneficial elaborative discussions during the early parts of the writing process. In her initial interaction with the Proposal found within ENG 101, Leah acknowledged the role played by this metatext to improve her topic for the summative assessment for the first unit:

I think that (the Proposal) definitely helped me, cause I was originally going to write like the typical love song. And when you (the instructor) had asked about, 'How are you going to make this (her original love song topic) different from anything else?' I honestly had no clue. I just remember like laughing, I was like, 'I wouldn't be able to write something unique that would, you know, be original and just be different.' So then I thought of one of my backup topics on gossiping and bullying, and I just kind of went off with that... But I do think those (Proposal) questions did help though, because again without that I probably would have just wrote the simple breakup song.

The importance, and key difference shown in this example, between the stage of the writing process paired with the Proposal and the Writer's Memo, is that the process and idea are in their infancies of what they will hopefully become in the final draft at the end of the unit or 
that specific writing experience. This is emphasized by Leah's laughter about not having 'a clue' about how to make a love song stand out compared to the cliché conventions. Meaning that the discussion prompted by the completion of the Proposal metatext positively impacted her song despite her enjoyment of the original main text idea pre-Proposal dialogue.

Despite Leah's advanced placement and honors English background in high school, her song idea had not yet been fully considered or outlined at this stage in her writing process. The long term thinking that the questions within the Proposal instilled thoughts earlier than they would have occurred to the student writer. Not only did the Proposal function as a way for her to discuss her ideas, but the feedback given by the response by her instructor (myself) contributed to an even further elaboration as she started to get feedback of some sort on that particular writing project.

Even the potential to have a more confident framework of thought to build off of for future conversations with other people, as shown by Brian's response to the uncertainty he felt for his career related second unit project idea, "I feel like this Proposal just helped guide me in the right direction. Of course I asked you (the instructor) later in the unit more detailed questions if I had them, but this was a good foundation." These proactive thoughts and writing experiences, a crucial component of longitudinal projects often requiring multiple discussions, are viewed as worthwhile by this student as he was in a new writing experience in FYC.

No matter what point in the life of a piece of writing that its writer is encouraged to provide elaboration or further discussion of the words initially written on a metatext, is generally perceived as a beneficial experience whether it helps the audience of the piece, how the writer reflects on or considers their work, and the kinds of in person conversations that can arise when all parties involved in peer review are given opportunities to read not only the core piece of 
writing being commented on, but the context providing metatext that provides the initial focus of these interactions. As focusing interactions with added information and metacognitive justifications, as shown by the study in Utrecht, creates comfortable opportunities for exploration and furthering of projects being worked on by writers/creators of all skill levels. To build on these benefits of 'discussion' and 'caring' the actual opinions that are brough to the table proved to be of further benefit when given the structural assisting metatexts.

\section{The Code of Perspectives (Angles/Lenses/Opinions) to Broaden and Reaffirm the Writer \\ - "And it made me think about how mine had no joking tone whatsoever, and how I maybe need to lighten it up a bit," - Tracy}

The final frequently occurring code directly involving connections between the student writers and their readers relates to the kinds of perspectives, angles, lenses, and opinions that are brought to the table, or changed/adjusted in some fashion, when responding to a draft and its metatext. Going along with the high frequency of this code, is a core reason why I enjoy teaching first-year composition, the wider variance amongst the interests of students compared to the more advanced 'English only' courses I have partaken in as a student.

The kind of class content and students within it aside, having people look at an idea, or in process project, is an activity that each of my five student participants held in high regard. When answering a follow up question about her frequently stated enjoyment of the strengths and focus areas in the Writer's Memo during our the third and final interview, Leah reflected on these values by elaborating that:

I think it's just, no matter what you're writing there's always room for improvement. And sometimes having a different perspective or different set of eyes looking at it, they might 
see something that you never would have even thought of. And I'm more than willing to accept that and hear about it, cause you don't always have to take someone's advice, but just to like, 'Oh, I didn't think about it in that way,' or 'Oh, this part didn't make sense.' The appreciation for getting the opinions of others, despite the acknowledgement of not always changing her work based on them, shows that hearing how someone else perceived or reacted to her writing is not only viewed as a positive if it changes something within her draft or ideas. This added a defined rationale as to why this connection to the activities with metatexts was applauded in the eyes of the students despite their ideas and main projects being incomplete or in the initial drafting stages. Because they were not the pieces at the end of the writing process that would ultimately be submitted for a large summative grade, it is that much more telling to the interest that student writers have in improving their work with the help of others.

The agency displayed in how student writers take in the words of others to consider, as well as potentially change, their work is seen in a study focusing on researching ways students (undergraduate and graduate) can and do engage with the feedback on their assignments mentioned in the literature review. A conclusion Margaret Price and her fellow scholars came to in said study is that "Students have a choice about whether to act on feedback. Their motives to do so or not may result from positive responses such as deep consideration of the feedback and reasoned rejection of it, or negative responses such as distrust of the feedback provider." (Price 279). This multilayered aspect of what causes students to implement the feedback they receive, or how they trust or appreciate said feedback/the person it comes from, is something that could also be its own longitudinal study, but still deserves acknowledgement in a study on structural assisting metatexts. This speaks to the prior two codes (Caring/Passionate/Proud and Discussion/Elaborate/Elaboration) as the amount of caring a writer perceived to receive from an 
audience member impacted how the outside perspective was received for the project at hand. Furthermore, the kind of discussion and elaboration that occurs within and as a result of metatexts is clearly influenced by the lenses brought to the project by the writer and readers that are interacting with it and the paired metatext. How much, or how little caring/effort, and discussion/elaboration occurs is heavily reliant on the people involved.

These somewhat uncertain qualities are also at play when analyzing the previous codes in terms of the connections student participants feel they had or did not have with their feedback givers and vice-versa. This can be alarming to an instructor, as we are aware that the best constructive criticism might come from someone that we do not find ourselves being friends with having the same beliefs on the topic of conversation as we do. However, it is intriguing that the spaces provided in the Writer's Memo allows for potentially personal/emotional vendettas or biases from either the writer or reader to be put through the structural requirements of this metatext. For example, the Writer's Memo does not ask if you 'like' or 'dislike' the topic, but rather what the writer feel the strengths, and areas of improvement are, and how the readers agree or disagree with these sentiments. Even with these added 'hoops' to avoid the outside personal interferences, it is still incredibly hard to narrow down these connections (or disconnections) between a writer, reader, and the project being discussed to a few qualities. But, the added channels provided by the metatexts, at least the ones used within this study, allows the perspectives on the work being assessed to shine through more than if they were unfiltered and unstructured.

The other metatext, the Proposal, has a less broad scope of perspectives involved (the student writer and the instructor) which, similar to the lack of commentary involving the Proposal for the code of 'Caring/Passionate/Proud' appears to have been a factor in not totally 
surprising the students in terms of the styles/kinds of opinions their teacher gave in response to the preliminary ideas.

A clear example of the filtering and focusing a student writer's perspective goes through thanks to the Writer's Memo is shown by the interest Leah had to read the work of her peers (during the first unit's song lyrics draft) without any added context/focus provided by the memo for a particular reason:

When I first read their songs, I read the song without the Writer's Memo, just to kinda get what my own perspective on it was and then afterwards I read the Writer's Memo. I think it helped a lot as far as, explaining parts of the story cause again, everyone's song was unique to themselves. And even my own song shared experiences, but it was very vague. So then when you read the Writer's Memo you're like, 'Okay, there's a little more to it than just the words on the paper.'...I thought the most important part was what they had questions about...for making sure you did the best you could.

The awareness Leah had of the limitations her thought process would have when analyzing the draft, without the background information of the Writer's Memo, further offers an avenue to explain why the student participants valued the structural assistance provided by a writer's metatext to get the full scope of the work. Thankfully, Leah didn't appear to feel she was incapable of helping out her peers, but understood that her knowledge (and thus feedback) could be benefitted by the process description and reflections provided by her peers' memos.

To parallel Leah's realization, Aspen's process in the course's first unit assessment did what a majority of the students did for any draft they received, and read a draft's Writer's Memo first, because of her desire to receive the information it provided about the work being reviewed: 
Reading my partners' Writer's Memos were very beneficial because I got to see what they were thinking and what was in their head. And it just made the song easier to read because I knew what they were thinking and why they went about writing about what they were writing. And without that, I feel like I would've interpreted things how I wanted and how I saw it rather than what they saw what they were meaning to talk about. Aspen's desire to best understand what her peers were trying to do reminded me of a common belief in pedagogy. That is, for educators to meet the needs and interests of the students rather than having the students always 'working up' to the instructor's level within the subject area. Yes, the pedagogical concept, Leah's preceding realization, and Aspen's similar views, all involve more work on the teacher/reader's part compared to potential proactive alternatives from the writer of the draft, but it did not appear to be a problem to Aspen (or Leah) to best help their writers reach whatever goals and ways of expression they had for the given assignment and its criteria. When readers do this, we aren't removing our own voices and perspectives, but trying to best make use of our own opinions in support of the writer through what are perceived as positives tools in metatexts.

To further show the interplay between the code of 'Perspectives' and the earlier analyzed 'Caring', Brian noticed a shift in his own perspective when reading the work of his peers by his third and final round of reading groupmates' Writer's Memos, this time in a unit based around life writing.

I feel like when we were doing our peer reviews, I feel like I got to them (his peers) because I feel that we have that closer connection, just cause we all have that better understanding of each other. Cause if you put people into one group and you ask them to read something about each other without their Writer's Memo, usually people won't 
really put that much effort into paying attention to the small details. I feel like because I understood what they went through I was engaged in the writing. I just wanted to help them because I know their actual story.

Because Brian's perspective changed by his deeper understanding of not only the writers, but the specific experiences they were referencing in their life writing drafts, he believed that his engagement with the writing and dedication to providing quality feedback was bolstered. The alternative scenario he makes reference to, of having peer review groups go into a session with little to no structure, or background information from the writers on their topics, is that the amount of effort and using their outsiders perspectives will be severely limited. Meaning that no matter the perspective a reader is coming into a text with, if they feel a sense of care and desire to help the writer, then they will take that extra time and effort to provide, what they feel, is helpful advice.

It's accurate to state that almost every instance of the perspectives (and the other listed synonyms) being brought up were directly related to a reader's view of a writer's draft. However, a potentially long term change in a reader's own projects came to the attention of Tracy. The particular lens she was writing her own second unit project (about practicing research writing related to her specific major and/or career goals) was called into question after she reviewed the work a pair of writers had that contained a different perspective and style:

Two people in my group, they were partners for theirs, they talked about how they weren't sure if they were sure if they had too much of a joking tone. And it made me think about how mine had no joking tone whatsoever, and how I maybe need to lighten it up a bit, because I felt like mine came across a little too informationally. 
Even if Tracy did not completely change the perspective she displayed in her writing, if she was able to 'lighten it up a bit', then it was undoubtably a positive experience for her to see how her groupmates were able to involve humor in their project. Thus, she felt like she was bettering her work for having been exposed to the work, and processes behind it, of her peers.

The entire purpose of having someone look at a draft, outline, preliminary idea, and/or brainstormed list is to have a different person give their thoughts on it in some way. The reactions to having these opportunities manifested itself in the code of Perspectives (Angles/Lenses/Opinions) being perceived as excessively beneficial comes as no surprise given the ability of metatexts to allow these perspectives to flourish for the kinds of focused feedback the writers desire, and for the readers themselves to better understand the person's own opinions that created the work being commented on.

Wrinkles are added to the dense concepts of perspectives by the interplay that existed in the commentary of FYC students due to the changes in the level of care/investment that exist between writers and readers, as well as the intrigue behind potential discussions or the elaboration that is provided by the writer and reader within the metatexts they use to communicate about the larger/main piece of writing. Two other supplementary wrinkles to a piece of writing that are more concerned with the project's writer are their individualized reactions to the amount of structure/accountability enforced upon them by the metatext, and the impact of a metatext on the student's creative process/writer's process. Essentially, each of the 15 codes in this study functions as a wrinkle (some enormous and some miniscule) to how the experience of crafting different kinds of summative writing projects in a college classroom but the ones that directly connected the writer, to the main project, to their audiences were viewed as 
beneficial inclusions with a metatext regardless of if the audience was fellow student writers or their instructor. 
CHAPTER V: ANALYSIS OF FINDINGS PART TWO: STUDENTS REFLECTING ON, AND/OR CHANGING THEIR STYLES BASED ON THE MIXTURE

OF AGENCY AND ACCOUNTABILITY

\section{Overall Code List Reminders and Intro To Takeaways Related to Common Codes Dealing with Interacting with Formatting of Metatexts/Writing Styles}

- "they (students) also get in the habit of examining their own work closely, thinking about their composing processes, and addressing themselves to a reader about what they have written, all valuable activities for developing writers" - (Sommers 80)

Due to the summary of my overall code list and the decision to spend my analyses on the five most common codes being discussed in the prior chapter, the opening of this chapter is dedicated to the remaining two of the five most prominent codes introduced in the previous chapter. What caused these final two codes (Structure/Accountability and Process/Writer's Process) to not be grouped with the other three that focused on the interactions of the student participants with other human beings, is the solitary and internal nature of this chapter's two remaining codes. The cognitive, intellectual, and rhetorical dynamics of how one individually adapts to a task's given structural requirements and how they adjust the ways in which they create the content within said task are what distinctly separates the codes in this chapter with the three in the last chapter. How this chapter's codes factor into structural assisting metatexts are the reflections of what they wrote, and how they wrote it, on the Writer's Memo and Proposal on an individual perspective. Whereas the prior chapter's codes were concerned with how the writer's individual actions impacted the interactions the writer had with their peer reviewers and instructor. 
This is not to say that there is a defined boundary between these two codes, and the previous three codes that emphasized the person to person aspect of the metatexts and the projects they were paired with. Rather, the student writers are considering their writing proactively by themselves, not just reacting to the commentary given by their peers and readers. These self-realizations, while still with the guidance of structural assisting metatexts, are extremely similar to what Sommers observed in his own implementations of his metatext, the Student-Teacher Memo. Sommers understood that through the repeated uses of a metatext, "they (students) also get in the habit of examining their own work closely, thinking about their composing processes, and addressing themselves to a reader about what they have written, all valuable activities for developing writers." (80). This shows the interplay, but also individuality, of how a student writer understands their own work/ideas while being responsive to the potential views and varying opinions of their audiences.

Connections between these two groups of codes and their large scale impacts for future studies and pedagogical uses of metatexts will be discussed in the conclusion chapter that follows this one. Additionally, the following list of the top five most commonly referenced codes in (the cumulative list of all 15 major codes recorded in the study can be found in the previous chapter) is presented here to serve as a reminder of the prevalence of these terms amongst the five student participants in the study.

\section{Top 5 Codes Used}

\section{Caring/Passionate/Proud 87 times total}

2.Process/Writer's Process 71 times total

3.Structure/Accountability 68 times total 


\section{Discussion/Elaborate/Elaboration 61 times total}

\section{Perspectives (Angles/Lenses/Opinions) 58 times total}

\section{The Code of Structure/Accountability to Keep Students on Track Beyond Editorial Work}

- cconsidering we needed to make sure we would meet the requirements. And I think that was super helpful, cause-there was so much, as your word would be 'agency' with this." - Leah

When it first became apparent of the frequency students were using the terms 'structure' and 'accountability' when documenting the results of the initial survey of students reflecting on their experiences prior to our FYC course, I was concerned that the participants' opinions of the structural requirements of our metatexts would appear to be frustration and/or confusion. This is because, with any restrictions to a student's complete agency, has the potential to be negatively received. In our FYC classroom, these restrictions were on the presentations of their own ideas and developing work could be detrimental to the long term utilization of either the metatexts themselves, or at least the concepts that are shown in these structurally assisting resources. Much to my relief, negative commentary occurred when students were reminiscing on prior schooling experiences in regards to what was taught and valued within peer review and structuring one's process in completing large assignments. Which means that any level of structure and accountability has the potential to be detrimental depending on the student and context it is set in.

The most jarring example of structure and accountability causing a loss in a student writer's agency is the blunt word and subsequent rationale that Tracy recalled peer feedback being in her high school English courses. Instead of being well-rounded or showing concern for a 
writer's individual desires, her courses demanded only two aspects of a paper be commented on. To give the word of, "Edit-it (peer review) was just a spelling and grammar revision process at my high school, it was basically synonymous to spellcheck or autocorrect.” Tracy later elaborated that while this style did improve her editing and grammatical skills, she believed it was causing her to miss out on the full potential of what it could be.

From the moment I read this, I was intrigued to see if her word would change at the end of FYC. Similar to how Leah's earlier analyzed answer to the same question of 'Yikes' transformed into 'Effort' by the end of the course. Tracy's original word developed as:

At the end I would describe it as 'strengthening'. This is because before I said 'edit' because I saw it as more grammar/spelling but our peer reviews focused more on actual content and message and our peer reviews helped me see how I could improve my overall message and not just the basics.

This comment is impactful for not only her feelings about how to strengthen one's work, but also what she thinks of the role that traditional editing plays. Tracy is not completely dismissing the importance of having smooth mechanics and deeply rereading your work to make editorial adjustments. It appears though, she is saying that reviewing written work involves what the work is saying rather than just polishing what is said regardless of if it is truly developed and supported in the work. The unique aspect of this is that if a writer truly wants someone to give grammatical or formatting feedback from their peer reviewers, the structural assisting metatext of the Writer's Memo allows for this to be included in a peer review experience. Along these lines, if a student writer shows concern for how to format or understand the grammatical conventions of the writing genre that the summative assessment is in during their writing of the Proposal metatext, the instructor can alleviate their concerns by helping to point them in the 
correct direction of resources or provide them with their own experiences within the respective genre. Therefore, with either of the two metatexts used in this study, the students had the agency to impose whatever structural based restrictions of what they desire feedback on from their peers or the instructor.

The prior quote within the ending survey showcased Tracy's more well-rounded opinion of peer review experiences with the help of structural assisting metatexts. This lends itself to the evolving understanding of the agency of metatexts in other research environments and for students with varying original preferences for deciding how to structure their commentary and desired feedback on their work. Bardine and Fulton's work analyzing their students' opinions on the Revision Memos (similar to the Student-Teacher Memo Sommers used) had their student, Andrea, who "began the semester not using revision memos as much as she should have; however, as the semester progressed, her focus moved from primarily grammar and punctuation issues to content, organization, and audience awareness issues. In her first revision memo of the semester, Andrea focused primarily on grammar." (151). Interestingly, Andrea initially used her agency with the metatexts to focus on the mechanics of her work, while Tracy seemed to relish in having the freedom to transfer the focus of peer feedback to the content and messages within her work. Both however ended up gaining a greater sense of value for the audiences of their works through repeated uses of their respective metatexts.

A common fear in education is that if students receive agency in their work, they will either skip or give minimal time and attention to structure and accountability instilling actions no matter the recommendations from their teachers. When asked a question about what long term planning she had done in her prior courses for larger projects, Aspen honestly replied that, "I usually don't make an outline and don't like doing it. Usually I just go for it and that works for 
me. I brainstorm in my head rather than on paper.” This initial mindset at skipping or having internalized bullet points at what a project draft will look like, has been a common sentiment from the students at any level of education I've been involved in. On the positive end, it showed Aspen's confidence in her internal idea formation ability. On the negative end, these students miss out on potentially beneficial understandings of what kinds of projects they benefit from structural requirements and having opportunities to format their work on paper before it is formally written.

Just like Tracy's initial feelings on peer review, I was curious to see what Aspen's thoughts would be on being obligated to write down her considerations and reflections on the various genres of writing within our three major units. After her final session of peer review in FYC, she was asked if the genre of writing impacted how she utilized the Writer's Memo. Despite being required to, unlike some of her high school experiences, Aspen had a change of heart on the value of this metatext:

I don't think it matters, because no matter what you're writing about or what you're doing, the Writer's Memo is set up so it's your planner for you. It's what you want to get out of whatever you're writing. Which is really nice because you could use it with anything and it helps you so much.

Even though the formal data collection, as well as the students' experience in first-year composition has ended, comments like Aspen's have made me hopeful of the longevity the concepts and writing/creating skills that our structural assisting metatexts promoted will have. This is especially hopeful given the vastly different kinds of projects and forms of writing/communication first-year composition students will find themselves completing and using when they fully enter their careers or progress further after their college experience. 
Aspen's stated progression of appreciating the benefits of putting your thoughts to paper pairs itself well with the need to force our students to practice interacting with these resources to hopefully open their eyes to new understandings and/or appreciations for metatexts' role in helping writers/creators. Bardine and Fulton realized the benefit of these forced practices within the composition classroom, "because of the structure of the revision memos, she (a student of one of the authors) is reading the comments written on her papers, something many students fail to do, and using them to improve future drafts." (151). This observation was first cited in this study's literature review to show what others in composition studies had to say about metatexts, it finds itself used in comparison with two excerpts of data in my own study, as all three consider the benefit of students experiencing actions with the help of a metatext. For Aspen, this was in her forward thinking of the end goals of her work, for the student in the Bardine and Fulton study, this was actively engaging with the feedback given to her.

Structural assisting metatexts in FYC courses can serve as a way to hold students accountable (as any form of graded assessment does) but if the accountability is combined with a level of agency/choice among the students that are being required to use said metatext, then it can provide tangible insights into the benefits of making student writers consider how to best make use of the accountability of the type of writing being completed, with the agency in the content and style of their work. For example, the third unit project had the prompt of students writing about an event/series of events in their lives that they believe made them either a better writer or communicator. Because they had the final say on the topic of their work, the Proposal for that project served as a way to require the students to start the preliminary stage of planning their desired topics. Leah made the connection between accountability while maintaining her own freedom of choice by saying that, thanks to the Proposal: 
I think I definitely felt more accountable, especially for the fact that we had to have multiple ideas, considering we needed to make sure we would meet the requirements. And I think that was super helpful, cause-there was so much, as your word would be 'agency' with this. There was so many things you could pick from, so being able to narrow it down to a few ideas.

Because Leah was able to agree with, and correctly use, the frequent term of 'agency' when using the Proposal to select a topic and explain her rationale, she recognized the importance of having a combination of accountability and agency to give structure to the numerous options she felt were available to her. This relates to Peter Elbows commentary first mentioned in the literature review, where having too little over agency about how a reader (in this case a teacher) evaluates the work of their students. With some only being allowed to use a letter grade or numbering of pre-selected qualities for their given 'task' of responding to student work. Elbow responds to these common confinements teachers face by saying, "Conventional grades inevitably mask different teachers' differential weightings of dimensions in multidimensional writing...Yet, another teacher with different values would give those two papers exactly the opposite grades." (307). As Leah relished the agency she had in her answers to the structural assisting metatexts, she alternatively might have had a much more negative outlook on the helpfulness of the structural requirements had the structure been much more restrictive about aspects of her authority over the kind of work she produced, as well as how she responded to the work of her peers.

The value of retaining some level of agency within a particular task, usually based on the content of a project or how a writer chose to answer questions within a metatexts, speaks to the 
human nature of responding to writing or writing prompts. Much like the importance of accepting that writing projects are for human readers and not machines or a higher power Arguably the most important aspect of involving any form of structure and accountability to an assessment designed for students is having defined and accurate purposes to these added wrinkles to a task. For Brian, it only took him one use of the Writer's Memo to believe that each of its areas (the writer describing their process, the draft's strengths, their desired areas of the most focused feedback from a reader, and any specific areas of the draft they would not want constructive criticism on) had a clear reason for their existence:

I think all of them (the four parts) had a purpose, like all of them had specific things, like different aspects, that made them their own unique thing...that made you look at your work specifically through that lens...So, to other people it might've felt like busy work, but to me, personally, it was beneficial.

Brian's belief that each part of the Writer's Memo caused the writer to, temporarily, focus their thoughts about their work through a particular 'lens' to the benefit of the reflective and proactive practices this metatext promotes, is a perfect example of the interplay between the five most common codes found. Wherein, because of the structure/accountability of the Writer's Memo, a writer's perspective changes to allow the elaboration on their writing processes. This shows their readers the level of care they have put into the main draft being reviewed, and the structural assisting metatext that provides the same accountability to the person giving feedback on the writer's ideas and/or work. And therein gives the main takeaway that became apparent with the code of structure/accountability for the majority of beneficial reflections, what purpose does these requirements have and in what fashion does the writer fulfill said requirements? 
The stylistic and rhetorical choices a writer decides to complete (to whatever degree meets their personal satisfaction) and whether the required structure/accountability of said task (the metatexts in this study) has a short or long term change on a writer's process serves as another connection between the two focus codes of this study. The clear benefits emphasized by the student participants of the structure/accountability code can now transition into what kinds of changes were created in the individual writer's decision making or routines for their future projects.

\section{The Code of Process/Writer's Process to Move Thoughts From the Mind to the Paper}

- 'the fact that we have a Writer's Memo and the fact that we have Proposals to help us narrow down our ideas more and help us solidify our ideas. I think that would be beneficial for more classes," - Brian

Of the five most common codes, the one with the most diverse uses was 'Writing Process/Process' when engaging with a metatext or the ideas/drafts they are in reference to. Given the structurally assisted agency of these metatexts, students had the cognizant choice of how they would answer the multiple metacognitive writing prompts within the texts when talking about the paired larger ideas or written drafts. Their antecedent knowledge and experiences definitively played a role in these diverse usages and emotions connected to them, as they were first year university students, virtually all of them went to different high schools. This meant that varying aspects of their typical writing processes, either imposed by their previous schools or their own independent choices, being disrupted stood out during each unit to each person. Much like every other of the five focus codes for these analysis chapters, 'Process/Writer's Process' could serve as an entire study by itself, especially given the different 
genres of writing and student writer's backgrounds that the metatexts were grouped with. But, within the three units in their FYC course, I was still able to discern several impactful excerpts to emphasize this code specifically amidst other references to codes either described earlier, or minor codes in the full list of 15 .

To start off with one end of the spectrum of how writer's prior memories of using metatexts in a writing process impacted their more recent projects, that being virtually no memorable metatextual resources in the case of Scotty. He not only lacked confidence as a writer, but also not recalling any formal peer review experiences prior to being in FYC. With the metatext focused on peer to peer interactions, Scotty used his lack of depth in this area to respond to the overall impact this had on his own actions at the semester's end:

The Writer's Memo was something I've never experienced before and it was very interesting to me. It allowed me to think about what I wrote and what I was writing to properly get my point across in my papers. It was beneficial because now I know that reflecting on my work is an important part in the writing process.

The tangible long-term benefits of Scotty's adjusted writing process will hopefully lend itself to the high levels of autonomy that he will encounter in his upperclassmen college courses and ultimately career field if he continues on as a criminal justice major.

Student writers that are less experienced in areas of self-reflection and analyzing deeper components of their writing had the potential to make gigantic strides in the options they became aware of what their explicit directions, initial obligations, and ways of answering the somewhat open ended questions that a Writer's Memo had on their written work. This self-reflection, paramount to both the Proposal and Writer's Memo, was found to also be tangible in Bardine and Fulton's work with their Revision Memo metatext, as their students were often, "Unfamiliar 
with the process of self-reflection and unable to step back and evaluate their own work objectively, most students sink into their comfort level of highlighting simple corrections and word changes. Through continued practice, as self-reflection becomes more natural, the students begin identifying larger issues and work to correct them." (152). Within my own study, Scotty did not fit into the 'most students' category, as he was not one to stick to the baseline corrections of mechanics and diction in FYC, as his Writer's Memos were more concerned with his audience's ability to understand the messages and context he provided them with in his drafts. Because he did not view himself (until the very end of the class) as a competent writer at all, his process appeared to center around the ability of his composed works to be evident to people that did not write the work themselves, meaning everyone in the class besides himself. Regardless, through the repeated experiences with this required reflective writings, Bardine and Fulton's students, much like my own student participants, were able to change the ways and amount of areas they are comfortable seeking explicit feedback for.

Further zoning in on the obligation components of metatexts, the Proposal, unlike more casual ways of having students reveal what their paper/project topics are, creates a sense of justification within the student writers. This is because they are explicitly asked to write about what inspired them to come up with their first choice topic ideas. This metatext also requires multiple backup options with rationales behind the student's potential interest in exploring them if trouble or a change of heart were to arise with their most desired topic. This proactive style of selecting a topic encapsulates the 'structural assisting' part of structural assisting metatexts. Tangibly shown in detail by Scotty's admission that, "The Proposal questions forced me to figure out my topic. I usually have a hard time coming up with one then I rush something that isn't as important to me. It held me accountable and allowed me to move forward with my 
writing much further." Scotty, as shown by all his quotes, struggled with multiple aspects of his writing process in prior English courses. However, the long term thinking he was able to have had been improved given that he did not procrastinate or 'rush' to select a topic he did not fully think through on all levels. So, if he believed that he could move forward with his writing 'much further' than if his typical writing process wasn't disrupted, then clearly the Proposal is satisfying what it was originally intended to do for composition students. That being, to provide structurally assisted agency to help students further progress as writers.

A student typically resorting to rushing their work in their process was also shown in Tracy's reflections. Despite her being a confident writer when it came to the structure/mechanics of her writing, as described earlier with her mixed views on peer review, she described the extrinsic motivation benefitting her work in FYC. The Proposal specifically caused this by her admission that:

I think I'm a pretty big procrastinator. So I feel like having to do the Proposal made me think more in advance and actually get excited to write the paper. If I hadn't done it I probably wouldn't be thinking about the paper until honestly like today, when it's due this weekend. So it just motivates me to actually get working on it.

By comparing the similarities between both Scotty and Tracy's different kinds of apprehensions, it boosts the credibility of the Proposal to positively adjust (at least temporarily) the steps a student goes through when completing a large summative assessment.

For students that do not experience procrastination and uncertainty in their topic selection when given a high level of agency, the Proposal can still add new layers to their already strong writing processes. Leah, the student participant with the most confidence and genuine interest in all areas of the course and writing, believed that the Proposal helped her step back and assess 
different options and how to frame her work instead of trusting her initial ideas for the long haul as she had done in previous classes:

The structured questions (within the Proposal) brought a new idea for myself as I am someone who doesn't always brainstorm. This 100\% helped with the structure and layout of each paper. Placement is very important in writing and many students struggle with putting all their thoughts to paper and make sure they're in a place that will strengthen the piece.

This statement blends together both of the focus codes of this chapter, as Leah recognized that adding a new part to her writing process (a reflective brainstorming session) would benefit other parts later on, such as the structure of her now more thought out ideas when they became written on her project drafts.

To build on the combination of positively interrupting a student's typical writing routine and their own framing of moving forward, Brian voluntarily made a valid connection of how both metatexts in our FYC class were related despite coming at different points of each project's timeline.

With the Writer's Memo, you should continue to do it, just because it helps people structure their ideas, in my opinion. People usually don't make their own outlines on their own if they're not given anything. So, the fact that we have a Writer's Memo and the fact that we have Proposals to help us narrow down our ideas more and help us solidify our ideas. I think that would be beneficial for more classes, for future classes.

Continuing the theme of this specific code of these seemingly 'necessary' obligations causing improvements in the quality of work and depth of thought that students put into varying components of bringing their initial ideas to a polished finished product. Brian, despite being a 
first-year composition student, is displaying the concept Peter Elbow views as advocating for 'good enough' evaluation with the addition of metatexts to the writing processes of an entire classroom community:

pragmatic realistic calculation: comparing the need for some evaluation (including how much information and precision is needed), and the harm or risk of untrustworthy results. If the need is great enough and the harm is small enough, then it makes sense to go ahead with it. This is what I mean by 'good enough' evaluation. (Elbow 303).

Both Brian and Elbow feel that disruption or inclusion of points of evaluation or reflection is worth the time and effort if there is a need for it and the potential harm is minimized to the people involved. In the case of the Proposal, this would be the choice on whether or not the student writer's and instructor's evaluation of the potential project ideas and desired resources to help the writer's process be successful is a worthwhile task. In the case of the Writer's Memo, it would be to decide on the need for a pause in the creating of a summative project for students to reflect on their incomplete work, and have others completing a similar project provide a different viewpoint and opinions on the writer's own reflections of their work.

Differences in reception of these metatexts based on the backgrounds of student participants were evident in the quotes described thus far. But considerations given to the differences amongst genres of writing or details in what is talked about within the metatexts deserve an emphasis as well when talking about the code's variance in usage. For instance, Tracy believed that what made her structurally assisted agency stand out for our second unit project (writing a draft of a research article connected to her major/career field) was the choice this project gave for students to determine their word count goals. Once again though, there was 
some structural assistance with this added dimension of each student setting a personal goal for their final draft between 1,000-3,000 words.

I think for the Proposal the biggest part that stuck out was the determining of my word count beforehand and that everyone had an individual word count that worked best for them. I feel like it kinda pushed me a bit, because I definitely could've ended that article easily at 1,000 words. But I went to 2,500, and getting to that point was beneficial because it pushed me to see what other information I could get out of me.

The self-motivation Tracy displayed is clear piece of evidence to support the long term potential of these writing process interruptions that any metatext, and any adjustments made to this text for a particular summative assessment. Meaning, if a student writer already possesses faith in their abilities beyond a tasks minimum requirements, then it appears that they can push themselves beyond what would satisfy their uninterrupted standards. Tracy knew that her article could be ended with 1,000 words, but her goal was a benefit to dig deeper into the selected topic of her research article.

In all of these specific examples using or referring to the code of 'Writer's Process/Process' additions or adjustments to the tasks a student does in order to meet whatever end goals they (or the instructor) have for a project are a textbook case of students having the choice to make a choice on how to use these interruptions. Along these lines, the student writers cognitively reflected on how much they will push themselves beyond what the structurally assisted metatexts require of them and how long of a time frame they impact the process. While there was already some crossover between the two individual and rhetorical codes of this chapter, the majority of the crossover analysis between individually focused codes and 
collaboration with others codes will occur in the conclusion to offer an overall reflection within this research setting and future setting contexts. 
CH VI: CONCLUSION: RECIPROCAL BENEFITS FOR STUDENT WRITERS AND READERS FROM METATEXT INCLUSION IN THEIR INDIVIDUAL AND COLLABORATIVE WRITING PROCESSES

\section{Overall Reflection on My Experience in This Research Study}

- "We try to learn what occurs in the research settings we join and what our research participants' lives are like. We study how they explain their statements and actions, and ask what analytic sense we can make of them." - (Charmaz 3).

As it mirrors with the preceding quote by Kathy Charmaz (sociology professor and director of Sonoma State University's Faculty Writing Program) the rationale for empirical qualitative researchers selecting to follow this research theory is based on the human element of their studies. In the case of my own research question, I wanted to better craft resources for my student writers in order to have them have agency over their project topics, what kind of feedback they feel would most benefit their work, while having consistent learning objectives and objectives that can any sort of topic can thrive within without losing the integrity of the desired information/message its writer wants it to represent. Thus, the wording of my overall research question being, "How do first year composition students use, understand, and value forms of structural assisting metatexts during the writing/creation process?" For the teaching profession as a whole, not just first year composition courses, this question hoped to justify, adjust, and improve the practices of the papers and projects assigned to students. The structural assisting metatexts within the research question are meant to offer students a mixture of student agency within an organized format to promote accountability and clarity to the students' desires for their respective projects. 
I could not simply assume, guess, or pose a more specific research question/hypothesis for the overall study while maintaining the principles that exist within grounded theory/empirical qualitative research. If I was hopeful for anything prior to my gathering of information and gathering of literature resources that I hadn't previously come into contact with, it was that the information (from my student participants and published scholarly work on metatexts in relation to the writing processes of students) would show that there can indeed be fruitful experiences for all students when they are allowed to make, at least some, of the decisions regarding what they do their summative projects on and how they would like assistance from their instructor/peer reviewers.

The words and connections of the study's participants have strongly indicated that FYC students place a high level of value and are extremely capable of understanding different uses of textual resources that require the writer to take ownership over what they want to create, and how they would like commentary of others to be structured to reach the loose structural requirements of a summative assessment. The previous educational memories, as well as the outside of academia experiences that cause resulting feelings brought into the classroom, were brought up directly or indirectly in the information gathered in the study. These informative responses the students shared indicated that, while there a plethora of ways of 'doing' peer review and levels of freedom an instructor/institution allows, first-year composition students generally appreciate and take the level of trust structural assisting metatexts offer them.

The two previous analysis chapters were separated by whether the codes, and the responses they came from, were mainly discussing other human beings (chapter four) or the cognitive, intellectual, and rhetorical dynamics of choice the individual writer/student takes in accomplishing their given task (chapter five). Because these two groupings of the five most 
prominent codes (Caring/Passionate/Proud, Discussion/Elaborate/Elaboration, Perspectives, Process/Writer's Process, and Structure/Accountability) exist concurrently with one another, more explicit connections between them fill out the following large sections of this conclusion, before finishing out with potential further research done by myself or other instructors.

\section{Connections Between Findings in Chapters IV and V (Purpose and Learning)}

- "By being candid about the purposes of the memos, I can begin to present them for what they are: an opportunity for students to take advantage of, rather than another judgment tool for the teacher." - (Sommers 78).

The writing scholar that one of my mentors Dr. Bob Broad cited when presenting his version of the Writer's Memo to us was Jeffrey Sommers. Sommers advocates for a blunt openness about why the metatexts (such as the Student-Teacher Memo referenced above) are being included as more than just busywork or checklists to grade a student. He and Dr. Broad are the original inspiration that I credit with involving metatexts in my pedagogy, show the innate value of learning in conjunction with the human interactions via text based writing. Given this, while the two analysis chapters were separated based on the social or individualized impacts of the metatexts, the chapters can build off one another to show that metatexts have tangible reasoning for their inclusion in a student's writing/creating process.

The key highlighted moment of purpose being realized by a student in Chapter 4, was based on when Leah saw the tangible reason for having the Proposal when another person (myself as the instructor) challenged her selected topic idea for writing her own song lyrics. Leah seeing this purpose is shown in her open reflection stating, "I was originally going to write like the typical love song. And when you had asked about, 'How are you going to make this (her original 
love song topic) different from anything else?' I honestly had no clue. I just remember like laughing." This quote was grouped in the code of Perspectives (Angles/Lenses/Opinions), but is comparable to the codes (Structure/Accountability and Discussion/Elaborate/Elaboration) used in Chapter 5. For this quote, Leah's interaction with her instructor served as a helpful disruption to her writing process. It would not have otherwise occurred unless she already had an internalized structure/accountability to seek out the opinions of her instructor early on. It is also individualized to Leah, as she explicitly wanted to write a typical love song when the entire class was given free reign on the topics of their songs. If some students were not able to see the purposes of both the Proposal, and Writer's Memo in the song lyrics project, they had two more opportunities with the other two summative unit projects. Which will automatically be somewhat different given the FYC projects each being on a vastly different genre of writing.

Aspen, when asked to comment on how she felt about using the Writer's Memo for different genres of writing in each project, firmly believed, "no matter what you're writing about or what you're doing, the Writer's Memo is set up so it's your planner for you. It's what you want to get out of whatever you're writing. Which is really nice because you could use it with anything" These acknowledgements of benefits, rather than uncertain activities that were assigned and tolerated, shows the mental connection students can develop with these metatexts. Despite it being an individual feeling, compared to the communicative aspect both structural assisting metatexts have between people. These interactions and development of the projects they are paired with, allow these comparisons between the analysis chapters to be justifiably made. For Aspen, she understood the Writer's Memo as a multi-purpose planning tool. If she wanted the conversation (textual or verbal) to go in a direction she desired with her peer review group. She 
felt she had agency over the core topics of discussion within her project draft, in addition to the potential depth of said discussion as the writer of both the draft and the Writer's Memo.

Another comparable direction between the two analysis chapters is described with the academic setting Harland et al. observed. Within science based courses utilizing peer review communications between classmates, "Being a reviewer helped students to learn about their own work, and it changed the way they understood the scientific literature.” (801). Something that science students in particular might not have had extensive or explicit experience doing prior to the study. Within a similar vein, a draft's writer being a reviewer of other own in-progress work (which is what other drafts' Writer's Memos serve to aide) shall hopefully have learning occur despite it being internally in the writer's mind, or directed towards the work of another person with the written and oral comments given on the draft. This learning and increase in perspectives of how to write their own projects can either be applied to the current draft, or future drafts/projects in and out of the classroom where these knowledge making experiences occurred.

The obvious distinction of reviewing another human being's work gives the reader differing viewpoints on how to present a particular topic. Tracy, expecting to only find conventionally professional and serious approaches to their research article summative assessment, states how a pair of classmates caused her to adjust her own emotion displayed in her draft, reflecting that her peers' Writer's Memo requested Tracy's commentary:

They talked about how they weren't sure if they were sure if they had too much of a joking tone. And it made me think about how mine had no joking tone whatsoever, and how I maybe need to lighten it up a bit, because I felt like mine came across a little too informationally. 
It cannot be known if the peer review process would've had the same impact on Tracy's finished research article project if she had not had the aide of the Writer's Memo to read the concerns of the writers. What can be validated through this metatext's involvement is the way it caused her to change her own work despite not having asked about it in her own Writer's Memo. This being counted in the code of Perspectives (Angles/Lenses/Opinions) despite not directly using any of those four words, is attributed to the focus of the quote; the perspectives of other people causing a change in another's. Not to be forgotten, Tracy's correlation with Chapter 5's internal focus is evidenced by the immediate change to her writing process for projects focused on her career, research assignments, and those that she feels fit a 'professional' format. Her original mindset can be traced to the prior ways these assignments had been outlined to her did not fit the multiple approaches she discovered thanks to the reading of another's metatext.

As Chapter 5 proves, the lack of input from other human perspectives thankfully did not seem to limit students' understanding that metatexts could still cause individual moments of learning to occur when they were completed by the writer themselves in relative isolation. That is, before their instructor or peer gave feedback from their Proposals and Writer's Memos, respectively. Brian believed that the Writer's Memo's descriptions and required components (which caused the following quote to be coded as Structure/Accountability) were helpful to his own considerations of his work regardless of the words his peers gave in response:

I think all of them (the four parts of the Writer's Memo) had a purpose, like all of them had specific things, like different aspects, that made them their own unique thing...that made you look at your work specifically through that lens... So, to other people it might've felt like busy work, but to me, personally, it was beneficial.

Unlike the observations of Harland and his peers, the class projects were not focused on 
one kind (scientific literature) of text being read and reviewed in this course. However, the student participants felt the benefits of the structural assisting metatexts were applicable for their own processes of reflections on one's own writing. Meaning that, whenever they find themselves in their major courses reading content correlated to their career/presumed strengths, they will be a higher level of analyst than if they had not had these learning experiences with described (and agreed upon) purposes of their writing process activities.

\section{Connections Between Chapters IV and V (Contrasting Negative Prior Experiences or}

\section{Alternative Learning Environments)}

- "the feedback process is considered limited in its effectiveness because, despite evidence of students' thirst for feedback (Hyland 2000; O'Donovan, Price, and Rust 2001), students do not necessarily read their feedback (Hounsell 1987) or, if they do, they may not understand or use it." (Price et al. 277).

The name 'first-year composition' is both accurate, as it is a course designed for freshmen in higher education, and misleading, as the students enter college with their own prior writing experiences that have played a role in crafting how they feel/proceed with the level of freedom new writing/creation experiences provide them with. One can hope that the diversity of K-12 educations, that fill any FYC course, will aide in the collaborative nature both of this study's metatexts require. However, the negative feelings students potentially come in the classroom with could deter them from fully embracing the full depth the metatexts allow them to.

The core reason for a lack of 'buying in' to textual resources is a saddening reality that was first mentioned in this study's literature review chapter. Scholars Margaret Price and her peers believed that having another person comment is an extremely desirable result of student 
writing. But their desire does not seem to be followed through on by the writers. As Price et al. hypothesized in this section's opening quote, the limitations of feedback in writing classrooms center around perceptions of the amount care put into the writing of feedback, and misunderstandings of what the feedback means for the project's progression. If these possibilities are accurate, for even a small fraction of a class's student population, then it means that a few of them have had less than fully experienced instances of feedback in the writing/creation process.

Along the lines of the feedback a writer receives after their project draft is read, the cognitive 'feedback' the writer gives themselves in the Writer's Memo creates a potential for the peer reviewing to understand and be inspired in how they give a different viewpoint on how the writer's project is perceived. So, a pleasantly surprising component of the code Caring/Passionate/Proud was the way that Brian, in Chapter 4, confidently stated that reading his peers' Writer's Memo helped his ability to get more out of the corresponding draft. And, in turn, a more caring form of peer feedback to his peers:

Theirs helped because they wrote about specific details in their paper that normally wouldn't stand out to a person reading their paper for the first time without any background or prior knowledge to it. So that's the stuff I kinda looked for, and when I found it I saw them in a new perspective and I have a better understanding of them when I read it. I don't know their experiences or what they've gone through, because I met them (his classmates) for the first time this year. And now that I read it, I feel like I got closer to them just from that.

Because the factor of how much a student 'cares' or the level of 'interest' they have towards the feedback they are receiving on their work was not mentioned in the Price et al. study, I believe that the metatexts used in this study played a key role in Brian having the 
observations he did about his increased desire to provide useful commentary to his groupmates after reading their Writer's Memo. The community atmosphere helped sparked by the usage of this metatext can also not be understated for the quality of work he feels he gave his peers. An example of the interplay between a student's typical academic timeline being positively disrupted was first displayed in Chapter 5, as it was placed within the code of Process/Writer's Process, is when Tracy stated her understanding of the 'forcing' the Proposal did to her creativity and justification:

I think I'm a pretty big procrastinator. So I feel like having to do the Proposal made me think more in advance and actually get excited to write the paper. If I hadn't done it I probably wouldn't be thinking about the paper until honestly like today, when it's due this weekend. So it just motivates me to actually get working on it.

Tracy, who frequently stated her confidence in the mechanical/grammatical aspects of writing, acknowledged her lack of motivation in starting a longitudinal project early on via the requests of her instructors. Just as Brian feels being obligated to read the Writer's Memos of his peers, Tracy's obligation to figure out and justify the topic/additional resources needed for her Proposal served as a way to counteract the habits she had created in other class settings. Both Brian and Tracy's level of trust they had in their abilities to produce quality work, worthy of being read by another person, hopefully shone through. This increased level of care, paired with the time allowed for students to complete their responses and read their feedback, offered the class more productive experiences than the ones described in Price et al.'s incomplete response/reflection experiences.

Price and her colleagues, at the completion of their peer review study, found that, just as I did, 'care' played a large part in the amount of seriousness they took considering the feedback on 
their work. When considering the negative impacts of memories in academic settings, the scholars relayed:

Students found it difficult to adjust their approach to dealing with feedback when it was less directive than they had been used to at school. They often felt that this was due to a lack of care from staff rather than the result of receiving a different type of developmental feedback appropriate in higher education. (282).

The less directive style of implementing/creating feedback, contrasted with the highly restrictive format of peer review checklists that do not include qualitative feedback and writer choice was a sentiment shared by a majority of the student participants. This structurally assisted agency exists independently, rather than being a traditional 'middle ground' of the two extremes. As the student participants frequently took note of how the work they did in creating their own Writer's Memos and Proposals served as focused ways of outlining future conversations with their reviewers. These comments were often the subject of quotes that were counted towards the code of Discussion/Elaborate/Elaboration. For example, Aspen felt that this unique reciprocal function of the Writer's Memo allowed her to have increased clarity for the two parties (writer and reader) that come into contact with the highly variable content of these writer's reflections.

I had a very positive experience with the Writer's Memo. The major takeaway for me was being able to pinpoint the areas I wanted help with. I was able to get clarification on exactly what I asked about. These experiences were very beneficial because it made it easier for me as the writer to ask for help on specific parts. As the reader it was very easy to be able to focus on the parts that needed help.

The value Aspen testified to above reveals that, while less direct than other teacher provided resources found in peer review activities, the structural assisting metatext made peer 
review scaffolded for students to reach higher levels, and have a blatant say in how these conversations would progress. The ability to have the peer review structured based on what the writer feels most warrants talking about from their current project draft, helped the reader dedicate ample time to these requested areas. As a result, the Writer's Memo is transformed from a less directive resource when the project's writer first sees it; but a very narrowed down guide when the reader views it. The clarity of the metatext's directions already combines the person to person aspect (Chapter 4) with the metacognitive and personal relationship to the metatext (Chapter 5). However, Aspen's observation was included in Chapter 4 because of the help she described it providing for the two different kinds of people that use the memo.

Scotty had much more introspective comments to offer, based on the absence of memorable, and purposeful, peer review instruction in his prior schooling. This differs from Price et al.'s beliefs that the less directive style of feedback found in college would be too big of a shift than what was shown in K-12 settings. In Scotty's case, the lack of a defined style of receiving/implementing feedback (as well as crafting it) created a sort of 'blank slate'. These relatively empty canvases, much like students that had well-established skills from prior classes, present opportunities to develop/adjust how student writers seek out and complete assessments of their own work. Scotty's discovery of how important these steps are served as a breakthrough moment for him, and myself as his instructor:

The Writer's Memo was something I've never experienced before and it was very interesting to me. It allowed me to think about what I wrote and what I was writing to properly get my point across in my papers. It was beneficial because now I know that reflecting on my work is an important part in the writing process. 
As Scotty directly stated in this realization, his writing process (coded as

Process/Writer's Process in Chapter 5) was positively developed by these semi-structured writing practices with the Writer's Memo. Not to be forgotten, the Proposal invited students to self-assess (on a smaller scale) possible project topics ideas and resources/assistance they would desire to accomplish the assigned project. Both of these metatexts reject the 'one size fits all' format found in other textual resources students have that purposefully limit the options. Instead, they promote a style that allows the student to fit their goals, and beliefs about them, to show others the care and effort they have put into their own ideas/work.

Within any new setting or task a person encounters, their feelings and actions within these new opportunities are the result (at least on a minor scale) of their learned and practiced skills. By allowing these skills to be expressed and developed in the ways that each individual student desires, especially for vastly different assigned projects, the ability to get the most out of the opinions of other their peers and teachers shall be more easily attainable. This is a much more equitable alternative compared to having restrictions are placed on these writers, or having them resort to only their independent decision making without the help of structure.

\section{First Resulting Möbius Strip: Communal Benefits from Individualistic Metatexts}

A Möbius strip is a mathematical concept of having a half-twisted loop with one distinctive side. However, it is non-orientable and contains the same starting/ending point. For the case of how it relates to this study, it refers to seemingly separate, but mutually supportive components of structural assisting metatexts and their human writers/readers, both of which are interconnected to one another's success in the course. Through analyzing the thoughtful words of my student participants, I discovered two distinct Möbius strips involving the usage of metatexts 
in FYC courses. To encourage the viability of these two Möbius strips, I will later emphasize my interest in being involved in researching, or reading about, future studies in different educational settings, student populations, and distinct projects to compare and contrast the findings of this initial study.

The first Möbius strip looks at how the classroom community benefits from individualized texts and activities. For individualized texts/activities, I am referring to the writer crafting their structural assisting metatexts through their own opinions and reflections, and the conversations that result from them. These actions result in a boost to the small group/whole class community. This can be traced to the increased amount of information other students learn about a draft's author, and the actual written piece being reviewed, via the accompanying metatext. For example, the first major writing project the participants were interviewed on was about writing their own song lyrics. The only major content requirement was that they had to have some sort of meaning behind them or personal connection to themselves. Due to FYC students typically having limited experience with one another, they would be at a disadvantage in terms of understanding the story behind the song, or why the author decided to select their song topic at this point in their academic/personal lives. A metatext providing further level of contextual info can also help the readers comprehend, and accurately interpret, the message the text's author is trying to convey through their creative song. An added bonus could also be if the peer reviewers mention unclear language that they would not be able to understand without the added descriptions provided by the Writer's Memo. The same can also be said for the Proposal for an instructor believing a student has thought through their topic enough to create a worthwhile summative assessment. Amongst the list of 15, several codes correlate well with this particular reciprocal relationship. Codes such as Perspectives (Angles/Lenses/Opinions), 
Discussion/Elaborate/Elaboration, Caring/Passionate/Proud, Honest/Honesty, and

Interest/Interested all can be viewed as pieces of evidence to support this theory from the larger quotes they are found within.

The two student participants that best emphasized this strip's presence throughout their quoted answers are Brian and Leah. In Brian's case, he frequently talked about how he felt his own, and other peer review group members', investment soar due to their metatexts and resulting conversations about the works. His quotes on pages 70,74, and 84 of this text epitomize this claim.

For Leah, she talked about appreciating the multiple voices that were afforded the luxury of hearing her topic rationale/goals (via the Proposal) and her opinions of the further developed written piece (via her Writer's Memo) made her effort more appreciated in her own projects, and the support she gave to her classmates' work. On pages 68, 77, 78, and 83 are, I believe are the best examples of her words supporting the prior statement.

This is not surprising to me due to the explicitly planned activities and responses to each metatext a student wrote in the course. However, it is especially endearing to hear that metatexts, and receiving project feedback as a whole, work well to boost the connections and engagement readers have with a work and its writer.

\section{Second Resulting Möbius Strip: Agency in Divergent Writing with Similar Requirements}

The second Möbius strip concerns the interplay between the two metatexts' structure and requirements, with the flexibility of both the Proposal and Writer's Memo of choice to apply the metatexts with varying genres of writing found in the course's summative assessments. Within the open-ended genres of writing, topics, and the content of a major project, having each project 
work within loose, but enforced, guidelines creates a sense of agency within an otherwise obligation orientated system. Due to higher education students, specifically those that are adolescents, exploring the intricacies of their current, or potential, majors can be a very daunting task to accomplish entirely on their own. The standout example of this was within the course's second project, which was to write a draft fitting the genre/content conventions of a major publication related to their field of study. The same requirements each student had to reflect upon in their Writer's Memo, and proactively consider in their Proposal, were what allowed them to give their contextual clarity and inner thoughts on this attempt at a professional piece of writing. Codes amongst the complete list that were frequently used in participant answers relating to this strip's accuracy are Structure/Accountability, Process/Writer's Process, Purpose/Goals, Confidence/Confident, and Potential/Improvement.

The two student participants that best emphasized this strip's presence throughout their quoted answers are Tracy and Aspen. For Tracy, the higher level of choice she had in FYC, compared to the prior schooling experiences focused entirely on grammatical/editorial feedback, made her survey/interview responses especially appreciative of the smaller amount of guidance the metatexts provided to promote a diversity in the content written within them. Her statements are best displayed on pages 69, 85, 99, and 102.

For Aspen, she felt a sense of ease and comfort when asking for assistance on her own work while offering the support that would best help her groupmates. She also referenced how this experience had changed how she treated proactive planning for her large projects. These quotes can be found on pages 76, 83-84, and 91-92.

In any class that is taught to more than one student, an educator's job is to offer equitable guidance that allows each individual student to succeed within the settings the class/activities are 
completed in. Therefore, hearing the enjoyment the participants had in this unique style of trust and accountability provided by these two textual resources makes myself, and hopefully any other readers, optimistic for ability of students to truly make their learning their own while meeting the standards set before them.

\section{Similar Future Studies and/or Research of Metatexts and Structurally Assisted Agency}

- "Assessment can also serve the purpose of advocacy, seeking to garner resources, change practices, and create beliefs through research. Obviously tied to integrity, advocacy can have an internal orientation for example, as one group of faculty conducts a study to persuade colleagues to revise course goals." (Hesse 144).

The core purpose of my initial research question, asking how FYC students use, understand, and value metatexts in the writing, was to gather and analyze data from the target audience of my pedagogy, the students in the classrooms I teach in. However, the target audience of this formally written study are educational administrators and my fellow teachers, at multiple levels/types of writing studies courses. Even non-composition focused courses, inside and outside a school's English department, often find themselves having a paper or presentation as a summative assessment that finds itself relying on the teachings of their school's English teachers to help the students craft quality content in the eyes of these non-writing studies instructors. If the assessments of writing project related pedagogical practices and resources are able to be presented to larger audiences, then the potential collaboration and cohesion across classrooms will be more likely to occur.

The goal of presenting pedagogical beliefs to a wider audience relates to the purpose of research offered in the opening quote by Douglass Hesse, University of Denver's executive 
director of their writing program. Who argues for the use of research as advocacy for changes on an institutional level within college writing programs. Despite the setting the quote is focused in, the words ring true for any research with a goal of advocacy in maintaining, adjusting, or completely changing how something in education is handled. Each of the previous chapters' analyses of this study's data and the comparing/contrasting to the work of other scholars has helped me add to the 'theoretical toolbox' I am developing as a newer educator, and even newer writing studies scholar. I welcome any future research to further, compare, and/or contrast the breakthroughs and data found in this study. Whether it concerns the main research question, using structural assisting metatexts, having different genres of writing working with the same resources to help a student's writing process, or experimenting with the amount of agency students are offered at different stages of their summative projects, I am eager to continue my own work as well as discuss these topics with my fellow educators. Ideally, I would love to engage in conversations about what students, staff, and parents of students feel 'counts' as ways of one putting in effort and care into their academic endeavors. Especially those that involve the work that leads up to summative projects.

\section{Applications in Other Educational Settings}

Given that this was my 'first' formal research with structural assisting metatexts, there are unique adjustments to replicating components of this study in different settings, different summative assessments the metatexts are paired with, and/or the kinds of student participants (as well as their antecedent academic experiences) involved with the data collection.

Specifically, something that I would change if I were to do a 'part two' of this study is to spend more time having students make note of/comment on the details of the kinds of feedback 
they received. I would have two separate questions in my participants interviews that would ask about the feedback they felt was the most, or the least, beneficial to their respective Writer's Memos and Proposals for each major project. In my opinion, my interview questions/data had a lack of detail as far as the definitions of what makes good feedback for definitive requests made in a writer's metatext that accompanies their project idea or project draft.

If I could complete this study in a different kind of higher-ed classroom, I would be intrigued to see the ability of business courses to implement the Writer's Memo and Proposal. Like English courses, business classes have a wide range of research based, but also creative avenues in paper/project based summative assessments. Both of which can mirror the different genres (song lyrics, research papers, and creative non-fiction) that were paired with the structural assisting metatexts that were in this study's FYC course. Several business majors, such as public relations, human resources, and marketing, thrive on the interactions with audiences in and out of their respective places of work. But this study would require some extensive research on summative assessment pedagogy within undergrad business classes. For this reason, the sources found in this incarnation of the metatext research were not focused on those kinds of business curriculums.

A different form of a 'part two' would be attempting to replicate this study/core research question in a high school English class setting. Based on my prior experiences as a secondary English education major, student teaching high schoolers, and personal accounts from people involved at that level of public education, there are several more obligations compared to the flexibility our professors had at institutions of higher learning. This added variable of 'teacher obligations' was not considered or talked about with my student participants. Despite this, there were several learning outcomes, a required textbook for each section, and an expectation of 
having at least three major units, each with their own summative assessment. Knowing that teachers working in K-12 settings have many more of these obligations/restrictive requirements given down to them, it is another possible opportunity to replicate the study and see what transfer exists with structural assisting metatexts and promoting student agency.

\section{Applications for Teachers Assigning Papers or Projects}

Because nearly all of my data focused on how students used, understood, and valued structural assisting metatexts, I decided it would benefit my readers to explicitly offer recommendations for teachers after this study's completion. My following recommendations for educators will concern how to model/teach structural assisting metatexts to students, planning out adequate time for students to fully experience the metatexts, and how to work within the restraints an administrative setting does, or doesn't, set for their instructors.

As mentioned in the introduction chapter, I have always been cognizant of providing my students with at least partially completed examples of any resource/project they are asked to complete. Typically, these examples create excellent opportunities to describe and elaborate on what they see on a screen or piece of paper. With something that was viewed as abstract to each of my student participants as a Writer's Memo or Proposal is, showing off the purpose before students do it 'for real' is something Bardine and Fulton, as well as Sommers agree with in their own metatextual writings described at multiple points of this thesis. By modeling it before students practice it themselves, it shall hopefully negate any busywork feelings students come in to teacher prescribed steps of a longitudinal project with. My student participants saw the purpose early on in the first unit project, but I would hope it would be apparent from the initial 
instruction if I had asked them that research question. Teachers need to have examples available, and thoroughly explained, in order to express

Based on the aforementioned unique traits of the metatexts, and how it does not meet the traditional 'middle ground' of the two typical extremes of student writer-reader communications, the scheduling of total time (mainly regarding in-class chances) is vital to the amount of effort students understand that goes into these agency instilling metatexts. While I cannot give defined minimum or maximum timetables for either metatext, as they are meant to be applied in multiple kinds of summative writing assessments, I can affirm that they are not something that is a 'outside of class only' kind of assignment. Much like the importance of modeling and explaining these resources, having in-class opportunities to ask questions to their instructor, and converse with their peers, offers the time to fully see the scope of what content could fill these agency providing frameworks. As justified by the student participants' level of value placed on the inperson discussions with their peer review groups, which started in their Writer's/Response Memos, one cannot underestimate the benefits these elaboration periods have for student writers.

A final focused piece of commentary I can give to educators wanting to involve structural assisting metatexts into their classrooms is to find ways to work within the level of trust and freedom your school administration offer you to take the reins with how assignments are assessed in the writing/creating process. Ways that choices are often limited include the number of topics in your students' summative assessments that are preselected, the approved source options students can cite in their assignments, and the amount of wiggle room in the project structure of paragraphs/components. For the Writer's Memo, thankfully, each of these three major limitations of the components of paper/project choice will not cause any of the four parts of this metatext to become impossible to complete. Each project is capable of being reflected 
upon in terms of what its writer feels are the process taken to craft it (1), the perceived strengths (2), apparent weaknesses (3), and any areas the writer is not comfortable receiving constructive criticism on (4). Conversely, any of these administrative restrictions will be a bigger hurdle for the Proposal to overcome. The Proposal is meant to 'propose' an original idea, backup options, and how the writer's peers, instructor, and course schedule can be tailored to help them achieve success. Thus, due to the limited range student projects have with an increase in restraining agency, Proposals may blend together when the instructor is responding to them. Students will need to dig deeper in how they describe their interests and subsequent goals in order to stand out to truly receive the most individualized feedback possible from their instructor. Facilitated by the responses their own work, and the corresponding metatexts, receive by their readers

No matter the restrictions, the two structural assisting metatexts are made to be applied to as many educational settings as possible. Just like the potential future research studies to further the findings in my own, I am eager to hear about, or apply on my own, metatexts in different schools with more limitations on how broad student projects can be.

\section{Final Answer to The Research Question, For Now...}

As I've hopefully made evident in the analyses that populate this and the previous five chapters, the biggest factors that result in how FYC students believe they've benefitted the uses, understandings, and values of structural assisting metatexts are directly correlated to several factors. Each of these factors (the 15 codes found in this original study) are tied to the human beings completing the metatexts and/or how the metatexts are formatted to ensure students are able to comprehend their purposes. To give a well-rounded review of the five most common 
codes, that served as the basis for the analysis chapters, here are how I believe all five work together in the study I conducted.

The care/passion/pride a writer or peer reviewer puts into each metatext, while highly variable, correlates to the reception of the reader of said feedback (from the non-project writer) or writer reflections (from the project writer). As a result of any amount of the level of care each person gives to their part of the metatext experience, the subsequent discussions/elaborations between writer and reader allows for an increase in the usefulness, level of understanding, and value placed on either the feedback a project had received, or the draft the reader viewed with the corresponding metatext.

Next, the structure of each metatext, which makes clear the accountability its writers/readers are held to and the freedoms they are afforded, allowed a 'best of both worlds' scenario of the most restrictive writing project resources, and the open-ended lack of requirements beyond a one-two sentence assessment prompt. The meshing of two different pedagogical ways of handling textual resources also connects to the innately different perspectives (lenses, viewpoints, and/or opinions) that are brought to the interpretations of how a person engages with the format of a yet to be completed metatext, and the responses to the content (of an already filled out metatext) they find within it.

Finally, the process/writer's process that a structural assisting metatext allows the student writers to have, at least temporarily, new, adjusted, or reinforced procedures to how they complete longitudinal composition projects. These reflective and inquisitive actions that each metatext asks the writer to include in their steps to accurately complete the components of their FYC course shall promote longitudinal learning. Or, if nothing else, new experiences to compare 
and contrast with their previous and future instances of creating writing-heavy projects in/out of academia. 


\section{WORKS CITED}

Bardine, Anthony Bryan, and Anthony Fulton. "Analyzing the Benefits of Revision Memos during the Writing and Revision Process.” The Clearing House, vol. 81, no. 4, 2008, pp. $149-154$.

Broad, Bob. "Strategies and Passions in Empirical Qualitative Research.” Writing Studies Research in Practice. Ed. Lee Nickoson, Ed. Mary P. Sheridan. Southern Illinois University Press, 2012. 197-209.

Charmaz, Kathy. Constructing Grounded Theory $2^{\text {nd }}$ Edition. Sage, 2014.

Elbow, Peter. "Good Enough Evaluation When is it Feasible and When is Evaluation Not Worth Having?" Writing Assessment in the $21^{\text {st }}$ Century: Essays in Honor of Edward M. White. Ed. Norbert Elliot, Ed. Elliot Perelman. New York: Hampton Press, 2012. 303-322.

Elliot, Norbert, and Les Perelman. "Strategies in Contemporary Writing Assessment: Bridging The Two Cultures." Writing Assessment in the $21^{\text {st }}$ Century: Essays in Honor of Edward M. White. Ed. Norbert Elliot, Ed. Elliot Perelman. New York: Hampton Press, 2012. 149154.

Harland, Tony, et al. "Student peer review: enhancing formative feedback with a rebuttal." Assessment \& Evaluation in Higher Education, vol. 42, no. 5, 2017, pp. 801-811.

Haas, Christina, et al. “Analytic Strategies, Competent Inquires, and Methodological Tensions in the Study of Writing”. Writing Studies Research in Practice. Ed. Lee Nickoson, Ed. Mary P. Sheridan. Southern Illinois University Press, 2012. 51-62.

Hesse, Douglas. "Writing Program Research: These Analytic Axes." Writing Studies Research in Practice. Ed. Lee Nickoson, Ed. Mary P. Sheridan. Southern Illinois University Press, 2012. 140-157. 
Journet, Debra. "Narrative Turns in Writing Studies Research." Writing Studies Research in Practice. Ed. Lee Nickoson, Ed. Mary P. Sheridan. Southern Illinois University Press, 2012. 13-24.

Price, Margaret, et al. "Feedback: all that effort, but what is the effect?." Assessment \& Evaluation in Higher Education, vol. 35, no. 3, 2010, pp. 277-289.

Sheets, Angela R. "Waking Dormant Researchers: Student Co-Research As Writing Research Methodology and Pedagogy.” Illinois State University, Department Of English, 2015. Sommers, Jeffrey. "Behind the Paper: Using the Student-Teacher Memo." College Composition and Communication, vol. 39, no. 1, 1988, pp. 77-80.

Stables, Andrew, et al. "Conceptions of effort among students, teachers and parents within an English secondary school." Research Papers in Education, vol. 29, no. 5, 2014, pp. 626648.

Sung, Yao-Ting, et al. "Evaluating Proposal for Experiments: An Application of Web-Based Self-Assessment and Peer Assessment." Teaching of Psychology, vol. 30, no. 4, 2003, pp. 331-334.

van den Berg, Ineke, et al. "Designing student peer assessment in higher education: analysis of written and oral peer feedback." Teaching in Higher Education, vol. 11, no. 2, 2006, pp. 135-147. 


\section{APPENDIX A: UNIT 1 RUBRIC (PART 1 DRAFT}

AND WM IN APPENDIX B AND C)

Tasks:

\section{Original Song Lyrics Rubric (150 Points Total)}

Part 1: Create an original song (300-750 words) with no more than 50 words taken from other titles or lyrics of other texts (songs, movies, shows, books, speeches, etc.).

Part 2: You will also have a breakdown (500-1250 words) of the MESSAGE (or messages) you write about in your song.

Part 3 (Uptake): A description of your thoughts throughout these tasks and the unit as a whole. What was you inspiration and process of making this song? You'll already be doing this before Parts 1 and 2 are formally assigned. But you are expected to add thoughts SPECICIALLY in relation to writing Parts 1 and 2 in addition to the previous unit activities and discussions. (minimum 750 words for whole unit). Some ideas can be taken from your informal uptake journal, but must be typed up/done more formally. The bulleted list under Part 3 is a list of suggestions of things you can talk about (if you'd rather talk about aspects of your process that are NOT listed under Part 3, that is fine as well as long you can justify their inclusion).

YOU MUST REFER TO AT LEAST 5 OF THE 7 CHAT TERMS IN EITHER YOUR UPTAKE (PART 3) AND OR MESSAGE (PART 2) OF THIS ACIVITY.

\section{Point Breakdown Part 1 (40 points) Part 2 (60 Points) Part 3 (50 Points)}

Part 1: Song (40 points)

- Length Requirement (300 words minimum, 50 words or less sampling from other works. Sampled parts must be credited after lyrics end).

- Contain components of music lyrics as a genre (from class brainstorm and discussion). At least 3 components of the genre must be clear to the reader you should list them too!

- Original work that can be inspired by another song (or songs) but must be different enough to stand on its own without the references or style of another work. It also must have a clear ending to be viewed as a 'complete' song and not a work in progress.

- Unique title followed by the instrumental music title and audio link to play along. The link cannot contain any lyrics or spoken words, only instrumental sounds as YOUR song lyrics are the words that go along with it! (-) 
Part 2: Message of the song (60 points)

- Length Requirement (500 words minimum, 1250 maximum for the assignment)

- Overall message of the song explained (not line by line, but what the text does as a whole/with all the lines combined)

- 3-5 Specific Lines broken down that might require more context than what is there (for this, don't pick a line that just says, "I love them" or "The grass was green") pick a line that might have multiple ways of being looked at or has imagery/unique ideas presented in it.

- If there are other smaller messages within the larger text, what are some of them? Where can they be found? (This part is not a requirement!)

- What inspired you to write your song with this core message?

Part 3: Thoughts on this task and overall unit (50 points)

- Length Requirement (750 words for whole unit, a good portion should be directly related to Parts 1 and 2.)

- Thought process on the writing of a song for a main unit assessment. Did you like this? Dislike this? Have you done anything similar to this in an English or Music class? A different class?

- What were some other ideas you had in mind for the song? (Message, background music, style of writing, genre conventions used)

- Did your thoughts change or remain the same on this concept now compared to the start of this unit? Why or why not?

- What were your thoughts on peer review during this unit? Significant conversations with your classmates in general outside of peer review?

Overall Grade and Comments $/ 150$

Overall UNIT GRADE (250 Points Total)*

*Considers the summative assessment, part 0, participation in class, HW, proposal for summative assessment idea, uptake, peer review. Peer review being the most valuable (2) 
APPENDIX B: UNIT 1 SAMPLE WRITER'S MEMO

(PAIRED WITH SAMPLE SONG IN APPENDIX C)

Writer's Memo Outline Format

\begin{tabular}{|c|c|}
\hline $\begin{array}{l}\text { What you did so far (describe your writing } \\
\text { processes to this point). }\end{array}$ & $\begin{array}{l}\text { I was inspired by my Part 0 song, John } \\
\text { Mayer's 'No Such Thing" where he } \\
\text { talks about the expectations placed on } \\
\text { graduating high schools students. I } \\
\text { twisted the concept to specifically focus } \\
\text { on the idea of 'settling down' and } \\
\text { finding a forever home and spouse by } \\
\text { the time previous generations did. } \\
\text { (Married, owning/renting a home, and } \\
\text { having child by 22). } \\
\text { The whole song is written, but I'm open } \\
\text { to adjusting concepts. }\end{array}$ \\
\hline $\begin{array}{l}\text { What you like about the current draft } \\
\text { (specific strength[s]) } \\
\text { Three Strengths } \\
25 \text { Words } \\
\text { Total Minimum }\end{array}$ & $\begin{array}{l}\text { I like the way I separated my stanzas. } \\
\text { It's VERY similar to how John Mayer's } \\
\text { song is separated, but the content fits the } \\
\text { stanza style regardless. } \\
\text { I think my music choice fits the song. I } \\
\text { love jazz and slower paced music, I } \\
\text { don't think my message/ideas are } \\
\text { something that can be rushed so I didn't } \\
\text { want the song to be rushed. } \\
\text { I like how personal the lines are to me. } \\
\text { They represent my goals and 'plan' for } \\
\text { when I do settle down. }\end{array}$ \\
\hline $\begin{array}{l}\text { What you want from your readers (two or } \\
\text { three specific and well-developed questions } \\
\text { and/or points of focus) } \\
\text { Two or more Questions } \\
50 \text { Words Minimum. } \\
\text { Provide Specifics such as } \\
\text { Quotes, Pages, and/or } \\
\text { Paragraphs. }\end{array}$ & $\begin{array}{l}\text { Do you think the song takes multiple } \\
\text { readings to understand the message? } \\
\text { What parts or messages were harder to } \\
\text { understand than others? } \\
\text { Am I being too negative or stereotypical } \\
\text { of the American dream? I don't want to } \\
\text { come off as if I'm saying, "It's NOT } \\
\text { okay if some people want that." If you } \\
\text { feel like I am being too hard on them, } \\
\text { what would you recommend changing? }\end{array}$ \\
\hline
\end{tabular}




\begin{tabular}{|c|l|}
\hline $\begin{array}{l}\text { No Go Zones (Things you don't want } \\
\text { constructive criticism on. No reason required, } \\
\text { but if you're comfortable explaining why, I'm } \\
\text { sure it would be helpful ()) }\end{array}$ & $\begin{array}{l}\text { While I'm comfortable with positive or } \\
\text { negative feedback on anything in the } \\
\text { song, I think it's important for my } \\
\text { readers to know that I don't want or plan } \\
\text { on having children in the future. I'm fine } \\
\text { discussing my reasons at a later time, but } \\
\text { I didn't want to include that in the song } \\
\text { lyrics to get the focus off track. So, I } \\
\text { reference adopting a dog or two and } \\
\text { possibly getting married to the right } \\
\text { person to subtly address this. }\end{array}$ \\
\hline
\end{tabular}




\section{APPENDIX C: UNIT 1 SAMPLE SONG LYRICS}

(PAIRED WITH SAMPLE WM IN APPENDIX B)

Joey Dundovich

\section{Settle Down}

(Played with "Traveling Music" by Ben Sidran, Bob, Malach, and Ricky Peterson) https://www.youtube.com/watch?v=gmlGLKtO-GU

Welcome to the real world they said to me

Sarcastically...

Take your life

Pick a spot and settle down for good

Well I never lived the dream of the kings and queens

Or those wealthy things

I'd like to think the best place for me

Is still hiding

In this world...

They love to tell you

Just pick a place and go

But a home is always better

When you take the time...

I wanna run on the beaches in Malibu

I wanna scream at the Super Bowl

I just found out there's no such thing as home

Just a place you're alive at for awhile

So the good girls and boys

Take the so-called normal track

White picket fences

And maybe a two car garage

Living their life

But it's contained by a lid

And all of our parents they're getting older

I wonder if they wished we would take it slowly

While they finish paying off their 30 year mortgages in maybe 29

They love to tell you

Just pick a place and go

But a home is always better 
When you take the time...

I wanna climb mountains in Denver

I wanna dance around in Times Square

I just found out there's no such thing as home

Just a place you're alive at for awhile

I am an independent mind

I am rather unique thinker

I am my own person

As long as I'm alive

Musical break for 5-7 seconds

I wanna adopt a dog or maybe two

I wanna find the woman of my dreams

I just found out there's no such thing as home

Just a place you're alive at for awhile

I just can't wait till my 10 year reunion

I'm gonna shock and awe the others

And when you see me at my absolute best

You will know what all this time was for...

\section{Select song Lyrics Taken from John Mayer's "No Such Thing"}

- Welcome to the real world they said to me

- Take your life

- They love to tell you

- So the good boys and girls

- I just can't wait for my 10 year reunion

- You will know what all this time was for 